\title{
1 Host environmental conditions induce small fungal cell size and 2 alter population heterogeneity in Cryptococcus neoformans
}

3

4

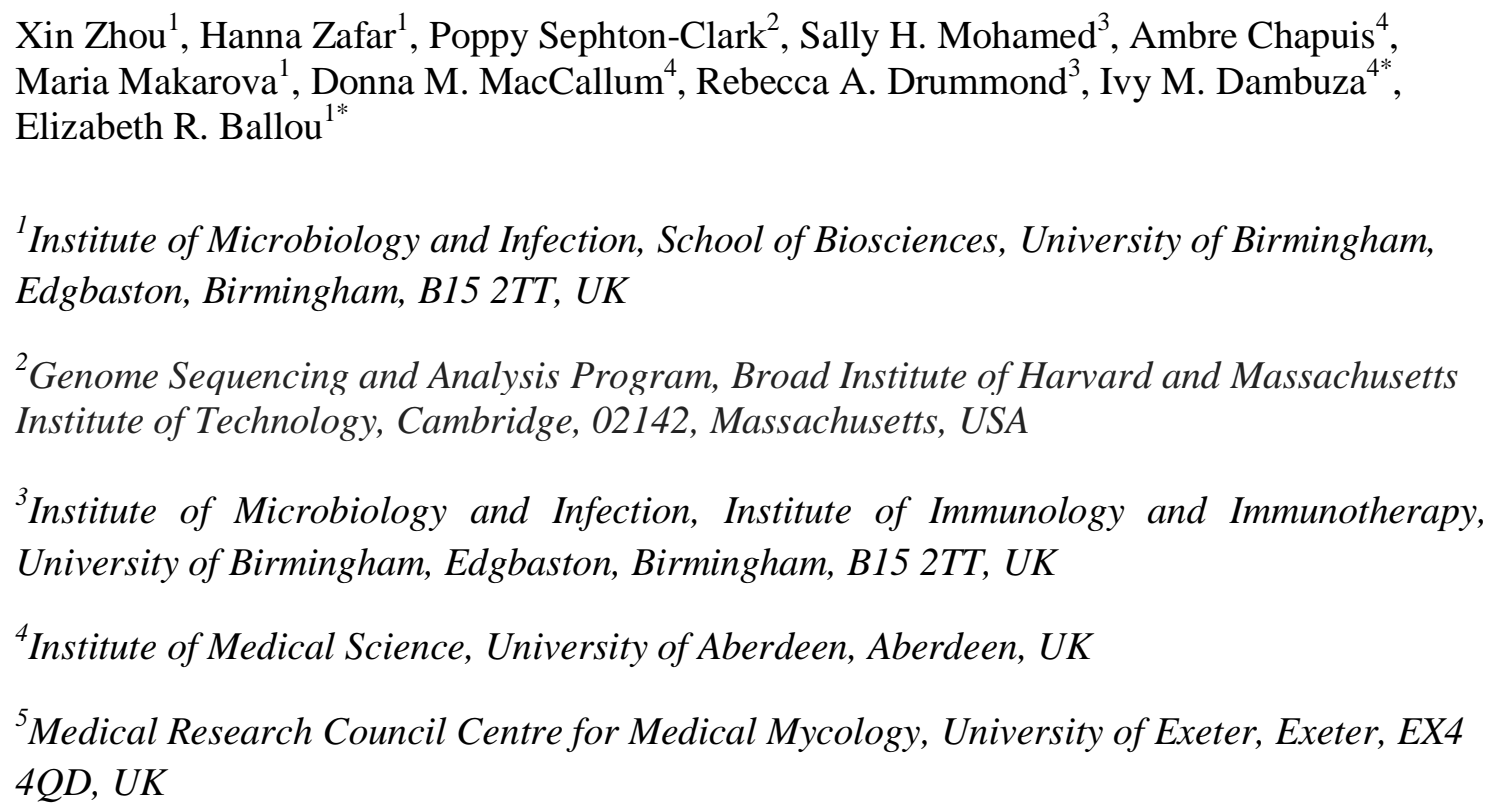
studentship (NC/R001472/1). PSC was funded by a BBSRC MIBTP PhD studentship. RAD and SHM are supported by the Academy of Medical Sciences (SBF004_1008) and the Medical Research Council (MR S024611_1). MM is funded by the University of Birmingham School of Biosciences. AC and DMM were supported by the NC3Rs (NC/N002482/1). IMD is funded by the Wellcome Trust (102705 and 097377) and the MRC Centre for Medical Mycology (MR/N006364/1). ERB is supported by a Sir Henry Dale Fellowship jointly funded by the Wellcome Trust and the Royal Society (211241/Z/18/Z). 


\section{Author summary}

34 The human fungal pathogen Cryptococcus neoformans causes 200,000 HIV-associated

35 deaths each year. In the lung, Cryptococcus makes an unusual yeast-to-titan morphological

36 switch that contributes to disease development by altering immune polarization and

37 introducing aneuploidy underlying host stress and drug resistance. Specifically, a proportion

38 of 5 um haploid yeast endoreduplicate and swell, converting to large (> $10 \mathrm{um}$ ) polyploid

39 titan cells that can then produce genetically distinct daughter cells. We recently developed an

40 in vitro protocol for inducing large titan cells and additionally observed a novel small

41 "titanide" cell type. Here we investigate the nature and origin of these small cells,

42 demonstrating that they emerge during both in vitro and in vivo mouse-passaged titan

43 induction in the well characterised lab strain H99 and are also apparent in a titanizing clinical

44 isolate, Zc8. We show that these titanide cells share features with titan mothers (lipid order)

45 and with spores produced during heterothalic mating. Finally, we show that the capacity of

46 clinical isolates to produce both titan and titanide cells impacts aneuploidy and the emergence

47 of drug resistance in vivo.

\section{Abstract}

50 Fungal morphology significantly impacts the host response. Filamentation and tissue

51 penetration by Candida and Aspergillus species are essential for virulence, while growth as a

52 yeast allows the thermal dimorphic fungi Coccidiodes, Histoplasma, and Talaromyces to

53 reside inside phagocytes and disseminate. The basidiomycete Cryptococcus neoformans

54 exhibits an unusual yeast-to-titan transition thought to enhance pathogenicity by increasing

55 fungal survival in the host lung and dissemination to the central nervous system. In a common laboratory strain (H99), in vitro and in vivo titan induction yields a heterogenous population including $>10 \mu \mathrm{m}$ titan cells, 5-7 $\mu \mathrm{m}$ yeast cells and 2-4 $\mu \mathrm{m}$ titanides. Previous reports have shown that titan cells are associated with enhanced virulence and the generation of aneuploid cells that facilitate stress adaptation and drug resistance, while small $(>10 \mu \mathrm{m})$ cells are associated with increased dissemination. However, the relationship between titan cells, small cells, and titanides remains unclear. Here, we characterize titanides and small cells in H99 and three clinical isolates and show that titanides share the lipid membrane order of their titan mothers and the $\mathrm{G}_{0}$ quiescent-like DNA staining of mating spores. In addition, we show that both titanizing and non-titanizing isolates exhibit altered capsule structure and PAMP exposure over time during in vitro culture, and generate aneuploidy in vivo. 


\section{Introduction}

68 Cryptococcus neoformans is a human fungal pathogen causing life-threatening pneumonia

69 and meningitis in immunocompromised and immunocompetent individuals [1-3]. In the host

70 lung, inhaled C. neoformans spores and yeast proliferate and can undergo an unusual

71 morphogenic switch from 5-7 $\mu \mathrm{m}$ haploid yeast to large $(>10 \mu \mathrm{m})$ polyploid titan cells with

72 altered cell wall and capsule organization [4-7]. This is a form of fungal gigantism, with

73 individual cells reaching 50 to $100 \mu \mathrm{m}$ [4-6, 8-10]. Titan cells also produce aneuploid small

$74(<10 \mu \mathrm{m})$ daughter cells, although the importance of these in disease progression is unclear [3,

75 11-14]. Titan cells enhance the dissemination and virulence of $C$. neoformans in animal and

76 mini-host models of infection [4, 5, 15-18]. Yet, titan cells block phagocytosis, and

77 phagocyte-mediated dissemination, of non-titan cells. Mutants deficient in titan cells exhibit

78 reduced virulence, and mutants that produce fewer small cells disseminate more slowly [15,

79 19-21].

80 A pressing clinical question is how titan cells influence patient outcome in a clinical

81 setting. Clinical isolates vary widely in their expression of known virulence factors including

82 capsule, melanin, and urease, a result of the wide range of infecting genotypes even in

83 relatively localized settings and within individual patients [13, 22-26]. Given this diverse

84 virulence portfolio, it is unsurprising that a screen of clinical isolates demonstrated that

85 fungal cell size alone is insufficient to explain in vivo outcomes [22]. However, two recent

86 analyses of clinical isolates highlighted a role for small cells in disease progression.

87 Following long term growth in capsule-inducing medium, Fernandes et al. observed either

88 giant $(>15 \mu \mathrm{m}$ including capsule $)$ or thick-walled micro $(<1 \mu \mathrm{m})$ cells in $C$. tetragattii and $C$.

89 neoformans isolates, respectively, and correlated this with CD4 clinical outcomes [13]. Rare

90 C. neoformans isolates that produced both giant and micro cells were highly virulent.

91 Mukaremera et al. also observed an inverse correlation between virulence in humans and the

92 presence of large cells following culture in DMEM+serum, conditions in which the virulent,

93 titanizing isolate KN99 $\alpha$ failed form titan cells [22]. Denham et al showed the emergence of

94 small cells in the lung over the course of infection and showed that small cells predominate in

95 the brain [19]. Together both studies suggest a role for small cells in infection progression,

96 however the link between small and titan cells remains undetermined. By studying H99 titan-

97 induced cultures, we identified a distinct small cell type which we termed titanides [14].

98 Titanides have distinct morphological properties: oval cell shapes, small cell size $(2-3 \mu \mathrm{m})$

99 and thin cell walls [14]. These are morphologically distinct from previously described micro 
100 cells (round, thick cell wall, $<1 \mu \mathrm{m})$ and drop cells $(5 \mu \mathrm{m})$, both of which have been

101 associated with in vivo infection [8, 27, 28].

102 Genetic and genome-wide analyses in C. neoformans H99 have shown that the yeast-to-

103 titan transition is a complex phenotype regulated by multiple interacting pathways[14, 20, 29-

104 31]. Titan cells have been observed in C. neoformans VNI, VNII, VNB, C. deneoformans

105 and C. gattii clinical and environmental isolates during growth in established in vitro titan-

106 inducing conditions that recapitulate the host environment [14, 29, 31, 32]. However, in

107 these conditions, we and others also observed a striking variation in size range and

108 morphology regardless of the presence of classic titan cells (>10 $\mu \mathrm{m}$ cell body) $[14,29,31]$.

109 Given evidence of induced population size heterogeneity across and within species, as well as

110 evidence demonstrating conserved genetic regulation of titanization across species, we

111 hypothesized that even in isolates that do not exhibit classic $>10 \mu \mathrm{m}$ "titan" cells, exposure to

112 in vitro titan-inducing conditions might trigger important changes in titan-related phenotypes

113 (size distribution, cell wall organization, ploidy, capsule), with implications for fungal

114 virulence.

115 To investigate this, we examined the impact of in vitro titan-inducing conditions on four

116 representative clinical isolates: $\mathrm{H} 99, \mathrm{Zc1}, \mathrm{Zc} 8$, and Zc12, selected based on their genetic

117 relatedness and their range of titan phenotypes: titanizing (H99, Zc8) or non-titanizing (Zc1,

118 Zc12). Here, we fully characterized these isolates and find that, like titanizing strains, "non-

119 titanizing' strains also display population heterogeneity in size distribution, cell wall

120 organization, and DNA content following exposure to inducing conditions. We identify

121 titanide cells both during in vitro culture and in vivo and demonstrate that titanides are the

122 progeny of polyploid titan cells, sharing their lipid membrane organization. Moreover, we

123 show that titanides share features of quiescent cells and spores. In addition, we find that the

124 'non-titanizing' Zc12 isolate, despite being defective in producing titan and titanide cells, do

125 produce small cells and can generate aneuploid offspring in vivo. Finally, we observe that in

126 vivo aneuploidy does not directly correlate with drug resistance. Together, this work confirms

127 the importance of small cells for disease progression, identifies titanides as a specific subset

128 of small cells originating from titan mothers, and raises questions about the role of population

129 heterogeneity in disease progression. 
132 In this study, we examine clinical isolates previously collected from the ACTA Lusaka

133 Trial in Lusaka, Zambia [26, 33]. We previously showed that Zambian clinical and

134 environment strains collected by Vanhove et al. vary widely in their capacity to form titan

135 cells, irrespective of originating niche or genotype [14]. Here, we further characterize

136 titanization in four strains- H99, Zc1, Zc8 and Zc12- selected based on their capacity to form

137 titan cells in vitro. In vivo induced titan cells are characterized by four defining features:

138 enlarged cell sizes, high ploidy, tightly compacted capsule, and the presence of a single, large

139 vacuole [6,34]. Using this definition, established by Nielsen and Zaragoza, we previously

140 classified Zc8 as titanizing, and Zc1 and Zc12 as non-titanizing [6, 14]. We also showed that

141 Zc1 exhibits reduced virulence compared to H99, and that all four isolates produce melanin

142 to comparable levels [14].

In vitro titan inducing conditions trigger a range of cell size and DNA content changes across four clinical isolates

All four strains are of clinical origin, have been fully sequenced and genotyped, and are genetically closely related (VNI). During standard in vitro YPD culture, cells were uniform in size, generally round with no defects in budding, and cell size was similar across and within all strains. To more fully characterize the impact of titan induction on all four strains, we first examined cell size distribution across the four clinical isolates under in vitro titanizing conditions. Consistent with our previous classification, H99 and Zc8 produce highly heterogeneous populations comprising titans $(>10 \mu \mathrm{m})$, yeasts $(>4 \mu \mathrm{m}$ and $<10 \mu \mathrm{m})$, and titanides ( $>1 \mu \mathrm{m}$ and $<3 \mu \mathrm{m}$ oval cells), while $\mathrm{Zc1}$ and $\mathrm{Zc1} 12$ populations are more uniform (Fig 1A). After 24 hours, cells $>10 \mu \mathrm{m}$ account for about $15 \%$ of the $\mathrm{H} 99$ total population, but only approximately $2 \%$ in Zc8 (Fig 1B). Moreover, induced non-titan Zc8 cells $(<10 \mu \mathrm{m})$ are smaller on average than induced non-titan $\mathrm{H} 99$ cells $(3.80 \mu \mathrm{m} \pm 0.10 \mathrm{vs} 7.15 \mu \mathrm{m} \pm 0.14$ SEM, $\mathrm{p}<0.0001, \mathrm{n}>200)$, and are smaller on average than Zc1 or Zc12 induced cells $(4.44 \mu \mathrm{m}$ $\pm 0.05,4.57 \mu \mathrm{m} \pm 0.06$ SEM, respectively, $\mathrm{p}<0.0001, \mathrm{n}>200$ ).

Given the low frequency of titans detected in induced Zc8 cultures, which can easily be missed when relying on cell counts with small numbers $(n=200)$, we assessed cell size spread and DNA content across the population of a large number of cells by flow cytometry (up to $\mathrm{n}=10,000)$. Using this approach, for $\mathrm{H} 99$ we observed population structure characteristic of typical and titan populations, with a minority sub-population of cells distinguishable as a shift to the right by forward scatter (FSC, a common proxy for cell size) (Fig 1Ci, n>8000) and 
165 DNA content $>4 C$ (12.3\%, Fig 1D, see Fig S1A for matched YPD controls). However, while

$1666.4 \%$ of induced Zc8 cells had DNA content $>4 \mathrm{C}$, this FSC shift was not apparent as H99

167 (Fig 1Cii). In addition, the median FSC of cells with >4C DNA content was lower than in the

168 H99 population, suggesting these Zc8 polyploid cells may be smaller than H99 polyploid

169 cells. Despite this overall reduction in frequency, a similar stepwise population of polyploid

170 cells with a long tail to the right was apparent for Zc8 (Fig 1D). Unlike H99, the vast

171 majority of cells in titan-induced Zc1 and Zc12 populations had DAPI staining consistent

172 with 1C DNA content. However, when we closely examined DNA content, we did identify

173 rare polyploid $4 \mathrm{C}$ cells in $\mathrm{Zc1}$ isolates $(2.8 \%)$ and $\mathrm{Zc12}(<1 \%)$. These cells were similar in

174 FSC to H99 4C cells, suggesting the presence of rare titan cells in the Zc1 and Zc12 cultures,

175 which likely require acquisition of larger sample size in order to detect (Fig 1C iii). These

176 data suggest that exposure to titan inducing conditions has a general impact on both clinical

177 isolate ploidy and cell size.

\section{Induced cells exhibit changes in PAMPs exposure}

180 C. neoformans titan and typical cells recovered from mouse lung have different cell wall

181 composition, with an increase in chitin and mannose (including mannan, mannoproteins, and capsular mannans) observed in cells $>10 \mu \mathrm{m}[7,18]$. We therefore asked whether similar differences could be observed in in vitro induced cells. Chitin (Calcofluor white, CFW), chitosan (EosinY), and cell wall mannan (ConA) were measured following exposure to inducing conditions for 24 hours. Microscopy and flow cytometry revealed an overall decrease in PAMP exposure following titan induction relative to YNB (Fig 2A, 2Bi, H99 representative plot). Gating on positively staining cells only, chitin, mannan, and chitosan staining correlated with cell size, with larger cells staining more intensely than smaller cells, the majority of which were below the threshold of detection (Fig 2Bii). Moreover, distinct high chitin populations were apparent in H99, Zc1, and Zc8 cultures (Fig S2). Quantitative analysis by flow cytometry using the same approach to identify titan cells as taken in Fig 1C again revealed a sub-population of large cells in all four induced cultures (Fig S2). Similar to

193 in vivo-derived $\mathrm{H} 99$ titan cells, in vitro-induced $\mathrm{H} 99, \mathrm{Zc1}, \mathrm{Zc8}$, and $\mathrm{Zc1} 2$ cells displayed a

194 distinct CFW-high population that correlated with the largest cells (Fig 2B, Fig S2) [7, 18].

195 The largest cells in all isolates had comparable chitosan and cell wall mannan staining to

196 typical cells (Fig S2). Moreover, in long-term induced cultures (72 h), overall size

197 heterogeneity was more apparent, with increased numbers of small cells and distinct high and 
198 low chitin peaks present in both Zc1 and Zc12 populations (Fig 2C). Together, these data suggest that changes in cell wall composition occur during low density growth in serum regardless of induction of cells larger than 10um.

\section{Growth in titan inducing conditions can alter virulence relative to yeast-phase growth}

Next, we assessed relative virulence of the four isolates using a wax moth larva model [35, 36]. When pre-grown in YPD, the non-titanizing isolate Zc12 was significantly more virulent than the other three isolates ( $\mathrm{n}=10$, Gehan-Breslow-Wilcoxon test, $\mathrm{p}=0.00070)$ (Fig 3A), killing a majority of larva within 5 days, whereas a majority of Zc8 infected larvae survived to pupation [37]. However, when cells were pre-grown for $24 \mathrm{hr}$ in titan-inducing conditions prior to infection, H99, Zc1, and Zc8 became as virulent as Zc12 (Fig 3A) [14]. Comparing the impact of inducing condition on the change in virulence revealed that no change was observed for Zc12, but induced Zc1, Zc8, and H99 cells increased in virulence relative to uninduced cells (Fig 3B). The observation that exposure to titan inducing conditions does not increase the virulence of $\mathrm{Zc} 12$ raised the question of what impact titan inducing conditions might have on $\mathrm{Zc} 1$ to alter its virulence.

\section{Cell density is sufficient to change capsule size and structure during capsule induction}

To further explore the differences in disease outcome resulting from titan induction, we examined capsule structure from yeast-phase and titan-induced stages. The $C$. neoformans cell wall is covered by a protective capsule, which not only impairs phagocytosis by macrophages, but also masks PAMPs from being engaged by host PRRs[38]. We first examined growth during incubation in $10 \%$ FCS at high cell density $\left(\mathrm{OD}_{600} 0.1\right)$, conditions established to induce robust capsule but not titan cells [14]. Capsule was visualized using india ink and the capsule to cell body ratio measured (Fig 4B, C). There was no relationship between wax moth virulence and capsule size: H99 and Zc12 showed an overall larger capsule size compared to Zc1 and Zc8 (Fig 4B) ( $<<0.0001, \mathrm{n}>100)$. We previously showed that the anti-capsule IgM antibody Crp127 binds O-mannosylation sites in capsular polysaccharide. In standard capsule inducing conditions, Crp127 binding was highly heterogeneous across and within all four strains, with both stained and unstained cells apparent (Fig 4C), consistent with our previous reports assessing binding during YPD and DMEM-induced growth [39]. As assessed by flow cytometry, H99 spanned unstained to high binding, with $51.8 \%$ of cells showing intermediate or high binding. For Zc8, the vast majority 
232 of cells are unstained (86.4\%), while $48.1 \%$ of cells from Zc12 exhibited intermediate

233 binding (Fig 4C).

234 Simply reducing the cell density leads to titan induction: $10 \%$ FCS at OD $_{600}=0.001$.

235 After induction, all isolates expressed robust capsule and were reactive to Crp127 IgM.

236 Analysis of capsule to cell body ratio for each of the populations revealed that Zc12 cells

237 display reduced capsule compared to the other isolates ( $p<0.0001, n>100)$ (Fig 5B). Across

238 the four isolates, binding by Crp127 remained heterogeneous, but binding patterns changed

239 compared to high density capsule induction (Fig 5A, C), consistent with our observation that

240 Crp127 binding is dynamic throughout titan development [39]. Similar to high-density

241 capsule induction, for $\mathrm{H} 99$ and $\mathrm{Zc12}$, more than $50 \%$ of the total population was positive for

242 IgM binding, but $\mathrm{H} 99$ staining was higher overall, while Zc12 remained more intermediate.

243 For Zc1, which was predominately negative for IgM under high-density capsule conditions,

$244 \sim 40 \%$ of cells became positively stained. However, for Zc8 the pattern was reverse: only $5 \%$

245 of Zc8 cells, the largest cells present, were positive for IgM binding, whereas a majority of

246 Zc8 cells were positive for IgM under high density capsule induction (Fig 4C, D). Together,

247 these data suggest that differences in cell density during exposure to inducing conditions

$248(\mathrm{OD} 600=0.1 \mathrm{vs} 0.001)$ significantly impact capsule structure, with a high potential for

249 altered capsule expression and organization across genetically related clinical isolates, even

250 in absence of large-scale cell size changes $(\mathrm{Zc1}, \mathrm{Zc12})$.

251

252 What are titanides?

253 Given the lack of correlation between conventional virulence factors and relative virulence in

254 the G. mellonella model, we asked whether there was a correlation with the presence of small

255 cells during infection. Specifically, we previously identified a third distinct cell type in

256 induced cultures: oval cells $2-3 \mu \mathrm{m}$ in diameter with thin cell walls and a clear, well defined

257 nucleus, which we termed titanides [14]. These cells emerge 24 hrs after serum exposure and

258 are the predominant cell type in H99 induced cultures after 3 days (Fig 1A, 6A). We

259 observed titanide cells in Zc8 in vitro cultures that shared these features (Fig 1A, 6A) and in

260 in vivo lung extracts (Fig S3A), where thick walled "micro" cells could also be observed.

261 Viability analysis of individual cells isolated from in vitro cultures by microdissection was

$262100 \%$ within 48 hours of serum induction for both $\mathrm{H} 99$ and Zc8 titanides. Titanides are

263 therefore distinct from previously described micro cells $(<1 \mu \mathrm{m})$ and drop cells $(5 \mu \mathrm{m})$, 
264 which have thick cell walls and, for the latter, disorganized nuclei and low viability [8, 27,

$26528]$.

266 We previously speculated that titanide cells are the daughters of titan mothers. To track their origin, we examined changes in subcellular membrane organization caused by titanization using the ratiometric dye di-4-ANEPPDHQ (Fig 6B)[40]. We observed that the plasma membrane in titan cells is significantly more ordered compared to yeast cells $(\sim 5 \mu \mathrm{m})$, which had lower lipid packing values (generalized polarization, GP) (Fig 6C). In cells $<3 \mu \mathrm{m}$, lipids in the plasma membrane were highly ordered, comparable to lipids in titan mother cells, further suggesting these cells are the direct progeny of titan mothers (Fig 6C). Finally, live cell imaging of in vitro titan cells revealed that titan daughter cells emerge every 90 minutes and are on average $<3.5 \mu \mathrm{m}$ in diameter (Fig 6D, S4), identifying these as titanide cells.

Examination of DNA content by flow cytometry for small cell populations revealed that when grown under inducing conditions, all four clinical isolates contained cells with apparent "sub-1C" DNA content, represented as stepwise peaks to the left (Fig 1D). These "sub-1C" populations were not present when cells were grown in YPD (Fig S1 ii). We speculated that these peaks might represent titanide cells, and in fact they are the smallest cells by FSC (Fig S1B). Microscopy to compare cell size in high density capsule inducing conditions vs. low density conditions also showed that these small cells are specifically generated under titan induction (Fig 6E).

Similar "sub-1C" peaks have been observed during flow cytometry-assisted cell cycle analysis of Saccharomyces cerevisiae and are representative of G0 or quiescent cells [41, 42].

285 We speculated that this peak might therefore represent G0 quiescent cells, suggesting that titanides might share similarity to $C$. neoformans spores produced by mating, which are quiescent prior to germination. To test this hypothesis, we first established that quiescent $\mathrm{C}$. neoformans spores exhibit sub-1C DNA content similar to S. cerevisiae quiescent cells. H99, Zc1, Zc8, and Zc12 MATalpha cells were crossed with KN99 MATa cells and incubated for 2 weeks to ensure robust sporulation. Zc1 and Zc12 formed robust hyphae and sporulating basidia after 7 days, comparable with H99. Zc8, a MATalpha isolate, exhibited a profound

292 defect in the formation of hyphae, with sporulating basidia rarely visible even after 3 months

293 (Fig S3B). The mating front, representing hyphae, basidia, spores, and some contaminating 294 yeast, was excised, and filtered through 40 um filters to exclude large particles. The resulting population was fixed, stained and analysed by flow cytometry alongside yeast-phase cells to 
297 positives using actively growing YPD cultures. This analysis revealed a "sub-1C" peak to be

298 a major population in robust mating reactions (H99: 37\%; Zc1:34\%; Zc12:53\%) and a minor

299 population (10\%) in the Zc8 mating front, in which basidia were rarely observed (Fig 6F,

300 S3B). Direct comparison to titan-induced H99 cultures revealed a similar "sub-1C" peak (8\%)

301 suggesting that this population represents quiescent G0 cells specifically generated during

302 titan induction.

\section{Modelling fungal-phagocyte interaction in vitro reveals strain specific phenotypes}

304 To better understand the impact of titan and small cells on disease development, we analyzed the infection process of all four strains following titan induction using an in vitro model. We observed significant variation in the percent of macrophages containing at least one internalized $C$. neoformans cell across the four isolates after titan induction, while YNB grown cells were phagocytosed similarly across the four isolates (Fig 7A). H99 showed the lowest macrophage infection rate and was significantly reduced compared to the other 3 strains (Fig 7A) (compared to H99: Zc1, p=0.0063; Zc8, p=0.0131; Zc12, p=0.0164). As shown in Fig 7B, for both H99 and Zc8, engulfed cells were typical cells (titanides and yeasts) rather than titan cells. Furthermore, capsule staining with 18B7 revealed that H99 titan cells physically associated with macrophages but were not engulfed (Fig 7C). We therefore asked

314 whether the reduced uptake of H99 cells overall relative to Zc8 (Fig 7A) is a consequence of

315 the higher proportion of titan cells in this population, similar to in vivo reports. Filtered titan

$316(>10 \mu \mathrm{m})$ cells or typical $(<10 \mu \mathrm{m}) \mathrm{H} 99$ cells were used to infect macrophages separately.

317 When only titan cells were present, the average macrophage infection was $21.6 \% \pm 5.5$

318 (SEM), while for typical H99 cells the rate was 82.2\% \pm 1.6 (SEM) (Fig 7D, p=0.0002,

$319 \mathrm{n}=500$ ), similar to uptake of the total populations for the three Zc strains. Mixed cultures of

320 titanized cells were co-incubated with macrophages in vitro and observed via time-lapse imaging for $18 \mathrm{~h}$. Intracellular Proliferation Rate (IPR), frequency of vomocytosis (vomo \%), and frequency of macrophage death $(\mathrm{M} \phi$ death \%) were measured. No significant difference in IPR was observed for the four strains, indicating that they maintain similar intracellular growth rates (Fig 7E). Zc8 induced the highest frequency of vomocytosis, although it was not statistically significantly different ( $\mathrm{p}=0.05$ vs. Zc12) (Fig 7F), but did induce significantly more macrophage death $(\mathrm{p}<0.001)($ Fig $7 \mathrm{G} ; \mathrm{n}=400)$. This suggests that there is no correlation between titanization capacity and vomocytosis or macrophage death. These results are consistent with previous studies in vivo showing that titan cells are more resistant to 
330 of smaller cells and further validate the overlap between in vitro induction and in vivo

331 induction $[5,12]$.

\section{In vivo titan inducing conditions match in vitro predictions}

334 Overall, in vitro phenotyping by microscopy and flow cytometry for cell size and DNA content predicts that: 1) $\mathrm{H} 99$ and Zc8 isolates will form titans in vivo, with the overall size of Zc8 populations smaller than that of $\mathrm{H} 99,2)$ a minority of Zc1 titan cells might be detected, 3) Zc12 will fail to produce detectable titans in vivo, and 4) small cells will be apparent for all four isolates and will proliferate to a similar degree within phagocytes. We therefore assessed all four strains in a murine inhalation model of cryptococcosis, the gold standard for determining titan capacity. C57BL/6 female mice were infected intra-nasally with $5 \times 10^{5}$ cells pre-cultured in sabouroud dextrose medium according to standard infection protocols, and brain and lung fungal burdens were measured after 10 days. Work using H99-derived mutants has demonstrated a role for titan cells in survival and proliferation in the pulmonary environment as early as day 7 [15]. When fungal cells from lung homogenates were analysed microscopically for titanization in vivo, similar size distributions were observed as seen in vitro (Fig 8A). Specifically, robust titanization was observed for both $\mathrm{H} 99$ and Zc8 (65\% and $68 \%$ of cells recovered from the lung, respectively, $>10 \mathrm{um}$ ), with Zc8 population covering a significantly smaller size range than H99 (Kolmogorov-Smirnov test for cumulative distribution, $\mathrm{p}=0.0001)$. A minority ( $8 \%)$ of $\mathrm{Zc1}$ cells were $>10 \mathrm{um}$. No Zc12 cells $>10 \mathrm{um}$ were observed. Similar to in vitro induced Zc1 and Zc12 cells, the in vivo populations as a whole were smaller and more uniform overall. All four clinical strains showed similar fungal burdens in the lungs on day 10 (Fig 8B, p>0.05) as assessed by CFUs, demonstrating similar capacities to proliferate early during infection. Moreover, brain CFUs analysed at day 10 post infection were comparably low across all four isolates, with Zc1 CFUs slightly higher than the others (Fig 8C; $\mathrm{p}<0.01)$. Taken together, these results support our predictions that in vitro titanization reflects in vivo titanization.

\section{Clinical isolates show different capacities to produce aneuploid colonies} improved stress resistance compared to typical cells from the same culture [12]. Our in vitro model predicts that high titanizing isolates $\mathrm{H} 99$ and Zc8 will yield greater aneuploidy in vivo.

362 It remains unclear whether ploidy variation in CNS cryptococcosis reflects the degree of

363 ploidy variation observed in the lung. However, because titan daughter cells are smaller on 
364 average and readily phagocytosed, we predict that ploidy variation following dissemination

365 to the brain will reflect the degree of ploidy variation observed in the lung. To test this, we

366 determined the impact of titanization on the genetic diversity of offspring and the impact on

367 different sites. We examined the ploidy of individual colonies originating from lung and

368 brain CFUs for all four isolates (Fig 9A, Fig S5, $n=30$ for lung CFUs, $n \geq 10$ for brain CFUs,

369 across 3 mice per isolate). Colonies were assessed within 72 hours of recovery from mice, at

370 the point when a small colony was just visible on YPD agar ( $\sim 36$ generations), a measure of

371 stable aneuploidy in the absence of environmental stress. Fig 9A shows the ploidy of

372 individual colonies relative to the median ploidy of all colonies from that particular lineage.

373 Interestingly, ploidy variation occurred for all isolates, including Zc12. There was no

374 significant difference in relative ploidy between colonies from lung vs. brain isolates for any

375 of the isolates. We observed that ploidy of H99 and Zc8 colonies varied widely, while Zc1

376 colonies were more uniform ( $\mathrm{p}=0.02$ compared to H99). This is consistent with a high degree

377 of titanization driving aneuploidy in $\mathrm{H} 99$ and Zc8 infections, and relatively low titanization

378 in the Zc1 isolate. However, we also observed widespread instances of aneuploidy in Zc12

379 CFUs, despite finding no evidence of true titanization in this strain either in vitro or in vivo.

380 Aneuploidy is associated with increased resistance to fluconazole, which continues to

381 be used as a frontline antifungal in resource limited settings. Fluconazole resistance in $C$.

382 neoformans is linked to aneuploidy of chromosomes $1,4,6$, and 10 due to the presence of

383 genes on these chromosomes that directly enable fluconazole resistance, however the

384 contribution of titanization to resistance remains unclear [43]. We therefore assessed the

385 impact of altered ploidy on drug resistance of individual colonies isolated from the lungs and

386 brains of infected mice (Fig 9B). Relative to parent isolates, we observed a wide range in

387 capacity to proliferate in the presence of fluconazole. The distribution of resistance for Zc12-

388 derived colonies was significantly limited compared to those of $\mathrm{H} 99, \mathrm{Zc} 8$, or Zc1 ( $\leq \leq 0.0002)$.

389 For H99, both fluconazole resistant and sensitive colonies were identified. For Zc8, colonies

390 with increased resistance to fluconazole tended to have increased ploidy, but a colony with

391 reduced overall ploidy and increased drug resistance was also observed. For Zc1, aneuploid

392 colonies were more sensitive to the drug. Within individual lineages there was no correlation

393 between increased or decreased ploidy and degree of fluconazole resistance $\left(\mathrm{R}^{2}<0.3\right.$ in all

394 cases). This is consistent with titanization facilitating ploidy shifts in progeny and with

395 aneuploidy in these isolates being random rather than specific amplification of chromosomes

396 involved in fluconazole resistance occurring prior to drug exposure. 
398

399

400

401

402

403

404

405

406

407

408

409

410

411

412

413

414

415

416

417

418

419

420

421

422

423

424

425

426

427

428

429

430

\section{Discussion}

The first clinical and murine model reports of cells consistent with giant/titan cells also reported significant size and morphological heterogeneity. Examination of cells from fungal abscesses revealed a highly heterogeneous population of cells ranging from 2-100 um[9, 10]. Consistent with this, infection of mice with laboratory strains yields a highly heterogeneous population comprised of large, polyploid titans and typical yeast as well as small, thick walled "micro" cells in lung extracts[5, 8, 20,44]. However, replicating this heterogeneity in vitro presents a challenge to modeling in vivo infection. When cultured on rich medium, clinically heterogenous populations become uniform, comprised of only typical yeast $[9,10]$. Moreover, this heterogeneity may be site specific within patients: clinical examination of $C$. neoformans isolates taken directly from CSF failed to identify cells that cross the defining 10 $\mu \mathrm{m}$ cutoff [45]. Whether this is because titan cells cannot escape the host lung or because the CSF environment is not supportive of de novo titan cell formation remains unclear $[34,46]$. Even during co-culture with immune cells that replicate host conditions and elicit titan cells, heterogeneity is not observed [44].

Some degree of heterogeneity is observed under capsule inducing conditions: Fernandes et al. reported that 5 days exposure to DMEM $\left(37^{\circ} \mathrm{C}, 5 \% \mathrm{CO} 2\right)$ yielded giant and micro cells and rare isolates that showed both giant and micro cells were significantly more virulent[47]. Interestingly, these authors also reported wide variation in size and fungal morphology within and between isolates and across serotypes [13, 47]. Mukaremera et al. also observed that strains that produce small cells were more virulent, using 5 days growth in DMEM+serum $\left(37^{\circ} \mathrm{C}, 5 \% \mathrm{CO} 2\right)$, conditions in which the high virulence titanizing laboratory isolate $\mathrm{KN} 99 \mathrm{a}$ failed to produce titans. However, neither group report observing the wide variation in cell size observed in established titan inducing protocols, nor do they observe small oval cells consistent with titanides[14, 29, 31]. Despite this, these works, together with the findings of Denham et al. reveal a role for small cells in infection progression [19]. While it is established that the presence of titans can affect drug resistance and host immune responses, contributing to poor disease outcome, the role of small cells is less clear [4, 5, 15, 20]. Therefore, a pressing question is the capacity of clinical and environmental isolates to generate population heterogeneity regardless of classic titanization capacity and the effect of this population heterogeneity on disease outcome.

\section{Investigating population heterogeneity in vitro}


431 Here, we expand upon the in vivo definition of titan cells to encompass the wide

432 phenotypic diversity observed during in vitro induction of three clinical isolates from the

433 ACTA Lusaka Trial in Lusaka, Zambia [26, 33]. Our data add to existing knowledge by

434 specifically studying clinical isolate titanization using an established in vitro titan induction

435 protocol. After in vitro titanization, C. neoformans populations are highly heterogeneous with

436 multiple sub-populations: titan (>10um), typical/small $(>4 \mu \mathrm{m})$, and titanide $(2-4 \mu \mathrm{m})$ cells,

437 as well as micro $(1 \mu \mathrm{m})$ cells $[5,8-10,14,44]$. Building on our previous findings, we used 4

438 clinical strains from the same genetic clade (VNI) which we previously identified as having

439 different capacities to produce titan cells [14]. These four strains are closely related based on

440 genome analysis, however evolved variation still exists between them.

441 All 4 strains demonstrated significant population heterogeneity after exposure to inducing

442 conditions, regardless of titan status. Relative to Zc8, H99 is strongly titanizing in vitro when

443 the in vivo definition (> $10 \mu \mathrm{m})$ is applied, but Zc8-induced cells exhibit overall population

444 structure consistent with titanization, including polyploidy $(>4 \mathrm{C})$, a relative increase in cell

445 size, and overall changes in PAMP organization. By combining microscopy and flow

446 cytometry, we propose a model in which predictive outcomes can be made about in vivo

447 strain "titan-signature" status. We additionally note that researchers can readily identify titan

448 cells through visual inspection of liquid cultures in tissue culture plates using bright-field

449 microscopy, with titans being large cells with a single vacuole and an intensely dark cell wall

450 apparent in $\mathrm{H} 99, \mathrm{Zc8}$, and Zc1 cultures, but DNA content analysis offers important

451 information about overall population structure (Fig 1A).

452

453

454

\section{Variation in cell size and morphology and impact on host cell interaction}

Population heterogeneity appears to be a general feature of titanizing isolates. Here we

456 observed that both titanizing strains $\mathrm{H} 99$ and Zc8 are highly heterogeneous after induction,

457 with three sub-populations that maintain distinct cell sizes and DNA contents. Moreover,

458 titan cells from both strains exhibit changes in PAMP exposure and capsule size and

459 composition, features important for the virulence of $C$. neoformans. Surprisingly, non-

460 titanizing induced strains $\mathrm{Zc1}$ and Zc12 also show population heterogeneity as measured by

461 DNA content and cell wall structure, despite a lack of true titan cells. Consistent with

462 previous findings, we directly showed that the presence of titan cells leads to decreased

463 phagocytosis rates of small cells [5, 12]. Denham et al. showed that at later infection stages,

464 in both lungs and brains the predominant population is the smaller cryptococcal cells around 
$46510 \mu \mathrm{m}$ in total diameter[19]. This matches our in vitro observation that in later titan-induced

466 cultures, the proportion of small cells increases, consistent with the increased replication rate

467 of titan mothers and the impact of cell culture density on the generation of new titan

468 mothers[14, 29, 31].

469 We additionally observed changes in capsule and IgM binding upon titan induction relative

470 to other capsule inducing protocols. IgM mediates complement-dependent phagocytosis and

471 has been shown to specifically inhibit the yeast-to-titan transition [48, 49].Interestingly, IgM

472 has been shown to be particularly important in the clearance of small particles $(2-5 \mu \mathrm{m})[50]$.

473 Our data here suggest differences in epitope exposure on small vs. large cells may exert a

474 protective effect by reducing overall phagocytosis. Future work will examine the impact of

475 titan induction on complement-dependent, opsonin-independent uptake and will address the

476 relative pathogenic potential of titanide vs yeast vs spores in murine models of infection.

477

478 How do titanides contribute to disease progression?

479 There is growing evidence of a high degree of genome plasticity during $C$. neoformans in

480 vivo growth [51-53]. Semighini et al. previously demonstrated, using comparative genome

481 hybridization arrays in H99-derived strains, that passage through mice in the absence of drug

482 stress results in large scale genome alterations, including aneuploidy, insertions, and

483 deletions [51]. Gusa et al. recently demonstrated that host temperature is sufficient to induce

484 transposon-mediated rearrangements in the C. neoformans genome [52].However,

485 titanization adds to and enhances this variation: titan cells produce aneuploid daughter cells

486 that promote in vitro stress resistance relative to yeast in the same population [12]. We add to

487 these previous reports by showing that high titanizing $\mathrm{H} 99$ and Zc8, low-titanizing Zc1 and

488 non-titanizing Zc12 isolates all yield aneuploid daughters to some degree when exposed to

489 the host microenvironment. We reveal that titanization can drive the emergence of aneuploid

490 offspring in the host by comparing the ploidy distribution of cells recovered from infected

491 mice. We observed large scale changes in genome content relative to parent isolates, and this

492 weakly correlates with degree of titanization (H99>Zc8>Zc1>Zc12). We hypothesize that, in

493 addition to strongly inducing titanization, during infection, the host microenvironment itself

494 is sufficient to induce aneuploidy and exerts a selective pressure, as has been observed for $C$.

495 albicans [54]. In line with this, we previously reported that daughter cell colonies derived

496 from in vitro-induced titan cells are mostly diploid, in conflict with reports from Gerstein et

497 al. that colonies derived from in vivo-derived titan cells are haploid or aneuploid $[12,14]$. 
498 This suggests that daughter cells derived from the two conditions may differ in their tolerance

499

500

501

502

503

504

505

506

507

508

509

510

511

512

to aneuploidy or capacity for genome maintenance. Fluconazole exposure, oxidative stress, and high temperature drive in vivo C. albicans aneuploidy, including whole ploidy reduction (diploidy to haploidy), individual chromosome aneuploidy (Chr 5), and segmental aneuploidy, and the same is likely true for C. neoformans even in the absence of titanization [54-57].

Future work will more fully probe the molecular mechanisms differentiating these clinical isolates and their impact on virulence.

\section{What is the environmental significance of "sub-1C" cells?}

Ashton et al. recently suggested that the existence of robust quiescent cells such as spores might contribute to the broad ecological distribution of specific sub-clades, however the rarity of MATа $C$. neoformans isolates in the environment suggests an alternate origin for these cells $[58,59]$. Here, we demonstrate that titanides observed in induced cultures originate from titan mothers and that these cells exist in a in G0-like state similar to spores generating by mating. Titanide cells have unique features including oval shape, smaller size and altered DNA content compared with typical yeast cells. The ability to induce titan cells in conditions likely to be encountered by Cryptococcus in the environment make it plausible that titan cells may form in the environment and are not just limited to patient lungs. In addition, we also we detected "sub-1C" populations from the Zc12 isolate in titan-inducing conditions, suggesting that the capacity to produce quiescent cells is not simply a consequence of high ploidy mothers. This raises the hypothesis that "quiescent" cells proposed to drive population expansion in environmental isolates may be generated via regulatory pathways driving titanization [58].

\section{Impact of population heterogeneity on drug resistance}

Gerstein et al. previously demonstrated that in vivo-derived titans provide daughters with a survival advantage compared to in vivo-derived typical cells[12]. Therefore, we predict the presence of titanides also contributes to disease progression by affecting drug resistance and stress adaption. Titan-derived colonies are resistant to fluconazole via aneuploidy of chromosomes $1,4,10,11$, and/or 12 when propagated in the presence of fluconazole, suggesting that titanization drives fluconazole resistance in vivo [12, 43]. Our data support these findings, with overall increases in population diversity in titanizing strains compared to non-titanizing strains following passage through mice (Fig 7A). However, we observed no specific correlation between increased ploidy and increased fluconazole resistance (Fig 7B). 
532 This is consistent with in vivo-induced aneuploidy being random with regard to particular

533 chromosomes, rather than a specific increase of chromosomes involved in fluconazole

534 resistance. Finally, induced but not un-induced cells from all isolates showed high but similar

535 virulence when using the galleria model and we found no differences in capacity to control

536 early lung fungal burdens during a mouse model of cryptococcosis. Our data therefore

537 demonstrate that in response to the host environment signals both non-titanizing and

538 titanizing isolates generate heterogeneous populations which will have implications for drug

539 resistance and host cell interactions. Future studies will investigate their impact on long term

540 immune responses including investigation of $\mathrm{T}$ cell polarization mediated by the different

541 clinical isolates.

\section{Acknowledgements}

544 We thank the doctors, patients, and their families involved in the ATCA Lusaka trial, without

545 whom this research would not have been possible. We thank the staff of the University of

546 Birmingham BMSU and the University of Aberdeen Medical Research Facility for their

547 assistance. 18B7 anticapsule antibody was a generous gift from Arturo Casadevall. Crp127

548 IgM anticapsule antibody was a generous gift from Robin May. We are grateful to Debbie

549 Wilkinson and Lucinda Wight in the University of Aberdeen Microscopy and Histology Core

550 Facility for their expert help with TEM experiments.

551

552 Materials and methods

553 Strains, media and growth conditions: All C. neoformans strains used in this study are

554 listed in Table 1.

555

556

557

558

559

\begin{tabular}{|c|c|c|c|}
\hline Strains & lineages & Clades & Source \\
\hline H99 & VNI & Clinical isolate & North Carolina \\
\hline Zc1 & VNI & Clinical isolate & Zambia \\
\hline Zc8 & VNI & Clinical isolate & Zambia \\
\hline Zc12 & VNI & Clinical isolate & Zambia \\
\hline CNV111 & VN1 & H99-derived & {$[60]$} \\
\hline
\end{tabular}

Strains were cultured routinely on YPD (1\% yeast extract, 2\% bacto-peptone, $2 \%$ glucose, $2 \%$ bacto-agar) plates stored at $4^{\circ} \mathrm{C}$. For mating reactions, cells were mixed from YPD plates with KN99a directly on Murashige Skoog agar (M5519 Sigma-Aldrich) and incubated in the 
560 dark at room temperature for at least 2 weeks. Titan cell in vitro induction was performed as

561 described in [14]. Briefly, cells were pre-cultured at $37^{\circ} \mathrm{C}, 150 \mathrm{rpm}$, in $10 \mathrm{ml} \mathrm{YNB}$ without

562 amino acids (Sigma-Aldrich) in which $2 \%$ of glucose was added according to manufacturer's

563 protocol. After $24 \mathrm{hrs}$, cells were normalized to $\mathrm{OD}_{600}=0.001$ in $1 \times \mathrm{PBS}$ (phosphate-buffered

564 saline) with $10 \%$ of Heat inactivated Fetal Bovine Serum (HI-FBS) (Sigma-Aldrich F9665)

565 and incubated at $37^{\circ} \mathrm{C}, 5 \% \mathrm{CO}_{2}$ for $24 \mathrm{hrs}$ unless otherwise indicated.

566

567 Galleria mellonella infection model: G. mellonella were purchased from LiveFoods, Ltd

568 (UK) and used within 3 days of arrival. Worms were maintained at $16^{\circ} \mathrm{C}$ until use, and only

569 worms lacking melanization were included in the experiment. Worms were allocated

570 randomly to each treatment group (10 per group), with the average weight of worms across

571 treatment groups maintained within $0.002 \mathrm{~g}$. Cryptococcus strains were incubated overnight

572 in YPD (5\% yeast extract, $10 \%$ bactopeptone, $2 \%$ D-glucose) at $150 \mathrm{rpm}, 30{ }^{\circ} \mathrm{C}$, or YNB

573 (and then exposed to $10 \%$ serum in PBS at $\mathrm{OD} 600,5 \% \mathrm{CO}_{2}, 37{ }^{\circ} \mathrm{C}$ for $16 \mathrm{hrs}$. Cells were

574 washed in sterile PBS, and then normalized to $5 \times 10^{6} / \mathrm{ml}$. Strains were randomly allocated to

575 the different groups. Worms were injected into the back left pro-leg with 20 ul innoculum.

576 Worms were maintained in the dark at $30{ }^{\circ} \mathrm{C}$ and observed for 10 days for survival, with

577 blinding for the identities of the different treatment groups. Survival was analyzed by

578 Kaplan-Meyer survival curve and significance was assessed by Log rank (Mantel-Cox) test.

579

580 Murine infection model: Female C57BL/6 mice were used at 8-10 weeks of age and were

581 maintained in individually-ventilated cages under specific pathogen-free conditions at the

582 Biomedical Research facility at the University of Birmingham (Birmingham, UK). Animals

583 were provided with food and water ad libitum. All experimentation conformed to the terms

584 and conditions of United Kingdom Home Office license for research on animals

585 (PPL/PBE275C33) and the University of Birmingham ethical committee.

587 Cryptococcosis Infection Model: Yeast was grown in SabDex broth (Sigma-Aldrich),

588 grown at $30^{\circ} \mathrm{C}$ with shaking for $18-24$ hours. Yeast cells were washed in PBS, counted, and

589 delivered to mice intranasally while under isofluorane anaesthesia. Animals were infected

590 with $2 \times 10^{5}$ CFU. For analysis of lung and brain fungal burdens, animals were euthanized and

591 organs weighed, homogenized in PBS, and serially diluted before plating onto YPD agar

592 supplemented with Penicillin/Streptomycin (Invitrogen). Colonies were counted after

593 incubation at $37^{\circ} \mathrm{C}$ for 48 hours. 
595 Preparation of Lungs for FACS: Lungs were removed aseptically from euthanized animals,

596 finely minced with a scalpel, and digested in digest buffer (RPMI supplemented with 10\%

597 FBS, $1 \%$ penicillin/streptomycin [Invitrogen], 1mg/mL collagenase D [Sigma], 1mg/mL

598 dispase [Sigma], $40 \mu \mathrm{g} / \mathrm{mL}$ DNAse [Roche]) at $37^{\circ} \mathrm{C}$ for 30 minutes. Digested lungs were

599 smashed through a $70 \mu \mathrm{M}$ filter, washed and red blood cells lysed on ice using BD

600 PharmLyse solution. Lung-isolated cells were washed in PBS/2mM EDTA, and then stained

601 with fluorophore-conjugated antibodies in the presence of anti-CD16/32 and 0.5\% BSA for

60230 minutes on ice. Samples were washed in PBS/0.5\% BSA/0.01\% sodium azide and

603 acquired using the BD Fortessa instrument equipped with BD FACS Diva software (BD

604 Biosciences). FlowJo (TreeStar) was used for the final analysis. Anti-mouse antibodies used

605 in this study were: CD45 (30-F11), Ly6G (1A8), Ly6C (HK1.4), SiglecF (S17007L), all from

606 Biolegend, and CD11b (M1/70), F4/80 (REA126), MHC Class II (REA813), all from

607 Miltenyi Biotec.

608

609 Cell wall staining: Cells from 24 hrs induced titan cultures were collected, washed twice

610 with 1xPBS and resuspended in 500ul McIIvaine buffer. Cells were stained with EosinY

$611(5 \mu \mathrm{g} / \mathrm{ml})$ in dark for 10mins and repeated for washes with McIIvaine buffer, then

612 resuspended in 500ul $1 \times \mathrm{PBS}$. CFW $(10 \mathrm{ug} / \mathrm{ml})$ and ConA $(50 \mathrm{ug} / \mathrm{ml})$ were added into

613 samples and maintained in the dark for 10 mins. After washing twice with $1 \times$ PBS, cells were

614 imaged with a Zeiss Axio Observer and analysed for fluorescent intensities with Attune NxT

615 Flow cytometer.

617 J774.1 cell culture: For most in vitro infection assays, we used the J774.1 murine

618 macrophage cell line. Cells were routinely passaged in Dulbecco's modifies Eagle medium

619 (DMEM+) culture media with serum (DMEM, low glucose, from Sigma-Aldrich; 10\% HI-

620 FBS; $1 \%$ penicillin-streptomycin solution from Sigma-Aldrich; 1\% 200mM L-glutamine

621 from Sigma-Aldrich). All assays were performed with cells in passages 4 to 10.

623 In vitro phagocytosis assays: The intracellular proliferation assay was performed as

624 previously described [61]. $24 \mathrm{~h}$ before infection, $1 \times 10^{5}$ macrophages $\mathrm{J} 774$ were seeded into

625 12-well plastic plates [62] in $1 \mathrm{ml}$ DMEM culture media with serum (DMEM+) and activated

626 with $10 \mathrm{U} / \mathrm{ml}$ IFN $\gamma$. Before infection, $C$. neoformans cells were collected from titanization 
627 culture and washed three times with sterile $1 \times$ PBS. After normalising to $1 \times 10^{6}$ cells $/ \mathrm{ml}$ in

$628300 \mu \mathrm{l} \mathrm{DMEM}+$, cells were opsonized with $10 \mu \mathrm{g} / \mathrm{ml}$ anticapsular $18 \mathrm{~B} 7$ antibody by

629 incubating at $37^{\circ} \mathrm{C}$ for $30 \mathrm{~min}$ [63]. Then opsonized C. neoformans cells were added into

630 activated J774.1 macrophages to give a multiplicity of infection (MOI) ratio of 10:1. After 2

631 hrs (time point 0 ), infected wells were washed at least three time with pre-warm $1 \times$ PBS until

632 all un-engulfed $C$. neoformans cells were removed from the wells.

633 Human monocytes were infected with opsonized cells for $4 \mathrm{~h}$ without IFN $\gamma$ activation, and at

634 this point all supernatants were collected for cytokine qualification. 4h post-infection,

635 monocytes were divided into two groups: with or without IFN $\gamma(10 \mathrm{U} / \mathrm{ml})$ activation and then

636 infection continued for another $20 \mathrm{~h}$. Total $24 \mathrm{~h}$ later, all supernatants were collected again

637 with LPS (100ng/ml) as a positive control added at the same time as fungal cells and

638 uninfected as negative control.

640 Macrophage infection rates: At time point 0, attached C. neoformans cells and

641 macrophages were stained with Calcoflour white (CFW, $10 \mu \mathrm{g} / \mathrm{ml})$ and Lyso-Tracker Red

642 (ThermoFisher, $1 \mu \mathrm{M} / \mathrm{ml}$ ) in dark for $10 \mathrm{~min}$ and then fixed with $1 \mathrm{ml} 4 \%$ paraformaldehyde

643 (PFA) in $1 \times \mathrm{PBS}$ at $37^{\circ} \mathrm{C}$ for $5 \mathrm{~min}$. After washing with $1 \times \mathrm{PBS}$, at least 5 frames from each

644 single infected well were randomly selected and imaged with Nikon Ti-E microscope,

645 capturing 500 cells. All images were analysed with FIJI and experiments were repeated 3

646 times for biological replicates.

648 Filtered Titans phagocytosis assays: After 24h of in vitro induction, H99 titanised total

649 population was passed through an $11 \mu \mathrm{m}$ filter to separate titan $(>11 \mu \mathrm{m})$ and typical cells

$650(<11 \mu \mathrm{m})$. Then both populations were washed, normalized and opsonize independently

651 before adding to infection assays. Activation and infection of macrophages with opsonized $C$.

652 neoformans cells followed the same protocol as described above.

654 Intracellular proliferation and vomocytosis assays. At time point 0 of phagocytosis assays, 655 extracellular cells were removed by washing with warm fresh DMEM+. All samples were 656 maintained at $37^{\circ} \mathrm{C}, 5 \% \mathrm{CO}_{2}$ in the Nikon Ti-E microscope chamber and imaged for $18 \mathrm{~h}$ via 657 time-lapse. Images were taken every $15 \mathrm{~min}$ and compiled into single movie files for analysis 658 using NIS elements or FIJI software. Movies then were scored visually for intracellular 
659 proliferation rate, macrophage death and vomocytosis percentage. Vomocytosis scoring

660 followed the guidelines described in Andrew et al., 2017 [64].

661

662 Flow cytometry for cell ploidy: Cells were fixed and stained according to the protocol of

663 [14]. Cells were fixed with 50\% methanol for 15 mins, washed 3 times with $1 \times P B S$ and

664 stained with $3 \mathrm{ug} / \mathrm{ml}$ DAPI. Cells were analysed for DNA content using an Attune NxT Flow

665 cytometer with violet laser. All flow cytometry data were analysed with FlowJo. Doublets

666 and clumps were excluded using recommended gating system of FSC-H vs FSC-A, which

667 was determined to be more parsimonious than SSC-H vs SSC-W followed by FSC-H vs.

668 FSC-W. Autofluorescence in the DAPI channel was excluded by comparison to unstained

669 cells. Gates for $1 \mathrm{C}$ and $2 \mathrm{C}$ were established with haploid controls cultured in YPD liquid

670 media as described in the text.

672 Cell sizes measurement: Cell diameter was measured using FIJI, with frames randomly

673 selected, all cells in a given frame analyzed, and at least 5 images acquired per sample for

674 each of two independent runs. Total cell number of each samples was $>200$. All statistical

675 analyses were performed using Graphpad Prism.

Measurements of membrane lipid order in vivo: Cells from $24 \mathrm{hrs}$ induced titan cultures were collected, washed twice with 1xPBS. Following resuspension in fresh medium containing $5 \mu \mathrm{M}$ di-4-ANEPPDHQ, cells were incubated for $30 \mathrm{~min}$ at $30^{\circ} \mathrm{C}$. Cells were then transferred into a glass-bottomed microscope dish. Imaging was performed on a Zeiss LSM 780 confocal microscope equipped with a 32 element GaAsP Quasar detector. A $488 \mathrm{~nm}$ laser was selected for fluorescence excitation of di-4-ANEPPDHQ. The detection windows were set to $510-580 \mathrm{~nm}$ and $620-750 \mathrm{~nm}$. The images were analyzed using a plug-in compatible with FIJI.

\section{Figure legends}

Fig 1. Titan cells formation varies among clinical isolates in vitro.

(A) C. neoformans cells from all indicated strains after $24 \mathrm{hrs}$ titan induction, Scale bar: $10 \mu \mathrm{m}$. (B) Cell body sizes of titan induced cells $(n>200)$. (C) Flow cytometry for cells after titanization with FSC-A as a proxy for cell size. i) Histograms for cell size (FSC-A) are shown for all indicated isolates with a dotted line indicating the distinct shoulder of size increase. ii) The gray sub-population indicates the size threshold identified for cells with DNA content $>4$ C. iii) FSC-A vs SSC-A scatter plots for all indicated isolates with a dotted line indicating the threshold for $\mathrm{H} 99$ cell sizes (D) Flow 696 cytometry analysis for DNA content after staining with DAPI. 1C and 2C populations were identified 
697 relative to YPD grown yeast cells from matched parent strains (Fig S1A).4C peaks were established

698 according to doubled MFI of DAPI staining relative to 2C. "T" indicates pre-titanized cells. For all figures, data for a representative biological replicate is presented $(n>3)$.

Fig 2. Non-titanising strains also exhibit population heterogeneity. (A) PAMPs staining for all indicated strains cells from both YNB yeast and 24hrs titan induction, Mannan (ConA, Red), Chitosan (EosinY, Green), Chitin (CFW, Blue). YNB grown yeast scale bar $5 \mu \mathrm{m}$; titanized cells scale bar 10 $\mu \mathrm{m}$. (B) Stained cells from (A) were analysed by flow cytometry to determine MFI indicating exposure of Chitin (CFW, right); Mannan (ConA, center); and Chitosan (EosinY, left). (C) Flow cytometry analysis of PAMPs staining for indicated cells from long-term(72hrs) titan inductions with MFI indicating exposure of Chitin (CFW, right); Mannan (ConA, center); and Chitosan (EosinY, left). "T" indicates pre-titanized cells.

\begin{abstract}
Fig 3. Disease outcomes varied from basal to titan-induced conditions on worm model (A)Survival curves of worms infected by YPD-grown or titan induced cells of four indicated strains. (B) Comparison of survival curves of worms infected with cells from both conditions. " $T$ " indicates pretitanized cells. For all figures, data for a representative biological replicate is presented $(n>3)$.
\end{abstract}

Fig4. Phenotype characterization of clinical isolates at yeast phase.

(A) C. neoformans cells from all indicated strains at yeast phase, Scale bar: $20 \mu \mathrm{m}$. (B) Total capsule and cell body diameters were measured and a ratio reported for each cell. $(n>100)$. ****: $p<0.0001$.(C) i) Representative images of capsule structure from capsule induction condition stained with both India ink and anti-IgM (Crp127) FITC(Green). ii) Histograms for IgM staining and gates show peaks for different levels of staining with corresponding frequency and MFI reported. Negative: cells failed to bind. Scale bar: $10 \mu \mathrm{m}$. For all figures, data for a representative biological replicate is presented $(n>3)$.

\title{
Fig5. Capsule structure from titan induction
}

(A) Representative images of capsule structure of titanized cells stained with India ink and anti-IgM (Crp127) FITC(Green); bar scale: 10 $\mu \mathrm{m}$. (B) Total capsule and cell body diameters were measured and a ratio reported for each cell. $(\mathrm{n}>100)$. ****: $\mathrm{p}<0.0001$. (C, D) Flow cytometry analysis of IgM staining with frequency and MFI reported. Ci) Gates show peaks for different levels of staining, with (D) corresponding MFI indicated. Cii) Size (FSC-A) vs IgM-FITC intensity, with different populations highlighted as in $(\mathrm{Ci})$. "T" indicates pre-titanized cells. For all figures, data for a representative biological replicate is presented $(n>3)$.

\section{Fig 6. Titanides from both in vivo and vitro}

(A) TEM of titanide cells from H99 and Zc8 from in vitro titan induction. Scale bar:500nm (B) Single-plane pseudocolored generalized polarization (GP) images. Color bar designates the range of GP values where red shows high membrane order and blues show low membrane order. Note plasma membrane zones were used to quantify mean GP values. Scale bar: $5 \mu \mathrm{m}$. (C) A plot representing mean GP values quantified at the plasma membrane region as a function of cell size in H99 cells.(D)Cell body sizes of titan daughters from live imaging of titan cells budding $(n=30)$. (E) Cell body sizes of all indicate strains after capsule induction( $n>100)$. [49] Flow cytometry for DNA content of mating fronts from the indicated isolates crossed with $\mathrm{KN} 99 \mathrm{a} .1 \mathrm{C}$ and $2 \mathrm{C}$ populations were identified relative to YPD-agar grown yeast cells from matched parent strains and MFI was recorded for sub-1C, 1C, 2C peaks. "T" indicates pre-titanized cells.

Fig 7: In vitro titan cells interaction with host immune cells.

(A) Infection rates for the 4 clinical strains, showing the percentage of macrophages infected with at least one internalized $C$. neoformans cell after $2 \mathrm{~h}$ co-incubation. Data were assessed as not normal by Shapiro-Wilk and analysed by Welch's ANOVA with Dunnett's test for multiple comparisons. 
${ }^{*} \mathrm{p}<0.02 ; * * * \mathrm{p}=0.0008$. (B) Representative images showing macrophages (Red, Lysotracker) infected with cryptococcal cells (Blue, CFW). Scale bar: $10 \mu \mathrm{m}$. (C) Macrophages infection rates infected with only titan or typical cells (typical cells $<10 \mathrm{um}$, titan cells $>11 \mathrm{um}$ ). Data were assessed for normality by Shapiro-Wilk and analysed by Student's T-test with Welsh's correction for unequal variance (determined by F-test). *** $\mathrm{p}=0.0002$. (D) Representative images showing macrophages (Red)infected with $\mathrm{H} 99$ yeast and titan cells. Fungi were co-incubated with anti-capsule antibody $18 \mathrm{~b} 7$ plus antimouse IgG-FITC (Green) and calcofluor white (CFW) for chitin (blue). Scale bar: $20 \mu \mathrm{m}$. (E-G) Macrophages and pre-titanized C. neoformans were co-incubated for 18 hours and assessed via live imaging for (E) IPR, [49] vomocytosis, and (G) macrophage lysis. (E) IPR: mean intracellular proliferation rate. Data were assessed for normality by Shapiro-Wilk and analysed by One-Way ANOVA. [49] Mf death \%: frequency of macrophage death indicated by cell lysis. Data were assessed for normality by Shapiro-Wilk and analysed by One-Way ANOVA. *p=0.05; ***p<0.001. (G) Vomo \%: frequency of vomocytosis. Data were assessed as not normal by Shapiro-Wilk and analysed by Kruskal-Wallis with Dunn's correction

Data for a representative biological replicate is presented $(n>3)$. "T" indicates pre-titanized cells.

\section{Fig 8. Titanizaiton and disease outcomes on mice model}

(A) Cell body sizes of fungal cells collected from murine lungs ( $\mathrm{n}>70$ cells for each isolate). (B, C) Infectious burdens for the indicated strains. Murine lungs (B) and brains (C) were assessed for dissemination 10 days post-infection via colony forming units of total homogenates ( $\mathrm{n}=5$ per strain). Data are presented as Log CFU/gram. (B) Data were assessed as normal by Shapiro-Wilk and analysed by One-Way ANOVA with Holm-Sidak's multiple comparisons test. Data are presented as Log CFU/gram. (C) Data were assessed as not normal by Shapiro-Wilk and analysed by KruskalWallis ANOVA with Dunn's correction for multiple comparisons. (D, E) Immune cell recruitment to lungs for the indicated strains. Lung homogenates were analysed by FACS for the indicated cell populations identified using the indicated markers for (D) Neutrophils (CD45+, CD11b+Ly6G+) or (E) Alveolar Macrophages (CD45+ Ly6C- Ly6G- CD11b- SiglecF+). Data were assessed as normal by Shapiro-Wilk and analysed by One-Way ANOVA with Holm-Sidak's multiple comparisons test.

Fig 9: Clinical isolates produce aneuploid daughter cells with altered drug resistance in vivo.

(A) Degree of heterogeneity in ploidy across the individual colony forming units recovered from host tissue. $1 \mathrm{C}$ and $2 \mathrm{C}$ populations were identified relative to YPD-grown colonies from matched parent strains and MFI was recorded for $1 \mathrm{C}$ and $2 \mathrm{C}$ peaks. Data are presented relative to median $1 \mathrm{C}$ MFI for all colonies for a given isolate. Data were assessed as not normal by Shapiro-Wilk and analysed by Kruskal-Wallis ANOVA compared to H99 with Dunn's correction for multiple comparisons. (B) Fluconazole resistance relative to parent for individual colonies aggregated in (A). Data are plotted relative to parent MIC and as a function of colony ploidy as assessed in (A). Data were assessed as not normal by Shapiro-Wilk and analysed by Kruskal-Wallis ANOVA with Dunn's correction for multiple comparisons.

\section{Supplemental Figures}

Fig S1. Supplemental information for DNA content analysis used Fig 3. (A) i) Histograms of DAPI staining intensity for YPD grown cells, and $1 \mathrm{C}$ and 2C peaks are indicated based on the MFI. ii)FSC-A vs DNA content scatter plots show the correlation of size increase with DNA content. (B) Single cells were identified by FSC-A vs FSC-H to remove doublets ( $\mathrm{n}>8000$ after gating), then were used for DNA content analysis (Left panel). FSC-A vs DNA content scatter plots show the correlation of size increase with DNA content (Right panel). "T" indicates pre-titanized cells.

Fig S2 (B) PAMPs staining flow cytometry analysis of induced cells from Fig 8 with large cells subpopulation highlighted in grey and MFI indicating exposure of Chitin (CFW, right); Mannan (ConA, center); and Chitosan (EosinY, left). "T" indicates pre-titanized cells.

Fig S3 (A) TEM of Zc8 titanides recovered from mice lungs, scale bar: 500nm. (B) Mating plates from the indicated isolates crossed with KN99 MATa. 
806

807

808

809

810

811

812

813

814

815

816

817

818

819

820

821

822

823

824

825

826

827

828

829

830

831

832

833

834

835

836

837

838

839

840

841

842

843

844

845

846

847

848

849

850

851

852

853

854

855

Fig S4 Live imaging of CNV111, expressing Nde1-GFP and Cse4-mCherry in an H99 background. Cells were incubated overnight in YNB, and then incubated in $10 \% \mathrm{FCS}, 5 \% \mathrm{CO}_{2}, 37^{\circ} \mathrm{C}$ at $\mathrm{OD}_{600}=0.001$ for 6 hours. Cells were immobilized in glass-bottom chamber wells using 1:200 dilution of Crp127 and imaged using a Zeiss Axio-imager at $63 \mathrm{x}, 36^{\circ} \mathrm{C}, 5 \% \mathrm{CO}_{2}$. Images were acquired every 10 minutes. The movie is representative of $>10$ biological repeats.

Fig S5: DNA content of individual colony forming units recovered from host tissue, L-M1: Lung of mice 1, B-M1: Brain of mice 1, dotted lines indicate median 1C MFI. $n=24$, except H99 samples from brains $(n=21)$ because of limitation of colonies recovered.

\section{References}

1. Park BJ, Wannemuehler KA, Marston BJ, Govender N, Pappas PG, Chiller TM.

Estimation of the current global burden of cryptococcal meningitis among persons living with HIV/AIDS. AIDS (London, England). 2009;23(4):525-30. doi: 10.1097/QAD.0b013e328322ffac.

2. May RC, Stone NR, Wiesner DL, Bicanic T, Nielsen K. Cryptococcus: from environmental saprophyte to global pathogen. Nat Rev Microbiol. 2016;14(2):106-17. doi: 10.1038/nrmicro.2015.6. PubMed PMID: 26685750; PubMed Central PMCID: PMCPMC5019959.

3. Denham ST, Brown JCS. Mechanisms of Pulmonary Escape and Dissemination by Cryptococcus neoformans. J Fungi (Basel). 2018;4(1). doi: 10.3390/jof4010025. PubMed PMID: 29463005; PubMed Central PMCID: PMCPMC5872328.

4. Zaragoza O, Garcia-Rivera J, Nosanchuk JD, Cuenca-Estrella M, Rodriguez-Tudela J, Casadevall A. Fungal Cell Gigantism during Mammalian Infection. PLoS Pathogens. 2010;6(6):1-18.

5. Okagaki LH, Strain AK, Nielsen JN, Charlier C, Baltes NJ, Chrétien F, et al. Cryptococcal cell morphology affects host cell interactions and pathogenicity. PLoS Pathogens. 2010;6(6):e1000953. doi: 10.1371/journal.ppat.1000953.

6. Zaragoza O, Nielsen K. Titan cells in Cryptococcus neoformans: cells with a giant impact. Curr Opin Microbiol. 2013;16(4):409-13. doi: 10.1016/j.mib.2013.03.006. PubMed PMID: 23588027; PubMed Central PMCID: PMCPMC3723695.

7. Mukaremera L, Lee KK, Wagener J, Wiesner DL, Gow NAR, Nielsen K. Titan cell production in Cryptococcus neoformans reshapes the cell wall and capsule composition during infection. The Cell Surface. 2018;1(1):15-24. doi: 10.1016/j.tcsw.2017.12.001. 8. Feldmesser M, Kress Y, Casadevall A. Dynamic changes in the morphology of Cryptococcus neoformans during murine pulmonary infection. Microbiology. 2001;147(8):2355-65.

9. Love GL, Boyd GD, Greer DL. Large Cryptococcus neoformans isolated from brain abscess. J Clin Microbiol. 1985;22(6):1068-70. PubMed PMID: 3905847; PubMed Central PMCID: PMCPMC271885.

10. Cruickshank JG, Cavill R, Jelbert M. Cryptococcus neoformans of unusual morphology. Appl Microbiol. 1973;25(2):309-12. PubMed PMID: 4121033; PubMed Central PMCID: PMCPMC380794.

11. Okagaki LH, Nielsen K. Titan cells confer protection from phagocytosis in Cryptococcus neoformans infections. Eukaryot Cell. 2012;11(6):820-6. doi: 10.1128/EC.00121-12. PubMed PMID: 22544904; PubMed Central PMCID: PMCPMC3370461. 
856 12. Gerstein AC, Fu MS, Mukaremera L, Li Z, Ormerod KL, Fraser JA, et al. Polyploid

857 titan cells produce haploid and aneuploid progeny to promote stress adaptation. MBio.

858 2015;6(5):e01340-15. doi: 10.1128/mBio.01340-15. PubMed PMID: 26463162; PubMed

859 Central PMCID: PMCPMC4620463.

860 13. Fernandes KE, Brockway A, Haverkamp M, Cuomo CA, van Ogtrop F, Perfect JR, et

861 al. Phenotypic Variability Correlates with Clinical Outcome in Cryptococcus Isolates

862 Obtained from Botswanan HIV/AIDS Patients. MBio. 2018;9(5). doi: 10.1128/mBio.02016-

863 18. PubMed PMID: 30352938; PubMed Central PMCID: PMCPMC6199498.

864 14. Dambuza IM, Drake T, Chapuis A, Zhou X, Correia J, Taylor-Smith L, et al. The

865 Cryptococcus neoformans Titan cell is an inducible and regulated morphotype underlying

866 pathogenesis. PLoS Pathog. 2018;14(5):e1006978. doi: 10.1371/journal.ppat.1006978.

867 PubMed PMID: 29775474; PubMed Central PMCID: PMCPMC5959070.

868 15. Crabtree JN, Okagaki LH, Wiesner DL, Strain AK, Nielsen JN, Nielsen K. Titan cell

869 production enhances the virulence of Cryptococcus neoformans. Infect Immun.

870 2012;80(11):3776-85. doi: 10.1128/IAI.00507-12. PubMed PMID: 22890995; PubMed

871 Central PMCID: PMCPMC3486048.

872 16. García-Rodas R, Casadevall A, Rodríguez-Tudela JL, Cuenca-Estrella M, Zaragoza O.

873 Cryptococcus neoformans Capsular Enlargement and Cellular Gigantism during Galleria

874 mellonella Infection. PLOS ONE. 2011;6(9):e24485. doi: 10.1371/journal.pone.0024485.

875 17. Chrisman CJ, Albuquerque P, Guimaraes AJ, Nieves E, Casadevall A. Phospholipids

876 trigger Cryptococcus neoformans capsular enlargement during interactions with amoebae and

877

878 macrophages. PLoS Pathog. 2011;7(5):e1002047. doi: 10.1371/journal.ppat.1002047.

PubMed PMID: 21637814; PubMed Central PMCID: PMCPMC3102711.

879 18. Wiesner DL, Specht CA, Lee CK, Smith KD, Mukaremera L, Lee ST, et al. Chitin

880 recognition via chitotriosidase promotes pathologic type-2 helper T cell responses to

881 cryptococcal infection. PLoS Pathog. 2015;11(3):e1004701. doi:

882 10.1371/journal.ppat.1004701. PubMed PMID: 25764512; PubMed Central PMCID:

883 PMCPMC4357429.

884 19. Denham ST, Verma S, Reynolds RC, Worne CL, Daugherty JM, Lane TE, et al.

885 Regulated Release of Cryptococcal Polysaccharide Drives Virulence and Suppresses Immune

886 Cell Infiltration into the Central Nervous System. Infect Immun. 2018;86(3). doi:

887 10.1128/IAI.00662-17. PubMed PMID: 29203547; PubMed Central PMCID:

888 PMCPMC5820953.

889 20. Okagaki LH, Wang Y, Ballou ER, O'Meara TR, Bahn Y-S, Alspaugh JA, et al.

890 Cryptococcal titan cell formation is regulated by G-protein signaling in response to multiple

891 stimuli. Eukaryotic Cell. 2011;10(10):1306-16. doi: 10.1128/EC.05179-11.

892 21. Gish SR, Maier EJ, Haynes BC, Santiago-Tirado FH, Srikanta DL, Ma CZ, et al.

893 Computational Analysis Reveals a Key Regulator of Cryptococcal Virulence and

894 Determinant of Host Response. MBio. 2016;7(2):e00313-16. doi: 10.1128/mBio.00313-16.

895 PubMed PMID: 27094327; PubMed Central PMCID: PMCPMC4850258.

896 22. Mukaremera L, McDonald TR, Nielsen JN, Molenaar CJ, Akampurira A, Schutz C, et

897 al. The Mouse Inhalation Model of Cryptococcus neoformans Infection Recapitulates Strain

898 Virulence in Humans and Shows that Closely Related Strains Can Possess Differential

899 Virulence. Infect Immun. 2019;87(5). doi: 10.1128/IAI.00046-19. PubMed PMID: 30833336;

900 PubMed Central PMCID: PMCPMC6479045.

901 23. Gerstein AC, Jackson KM, McDonald TR, Wang Y, Lueck BD, Bohjanen S, et al.

902 Identification of Pathogen Genomic Differences That Impact Human Immune Response and

903 Disease during Cryptococcus neoformans Infection. mBio. 2019;10(4). doi:

904 10.1128/mBio.01440-19. PubMed PMID: 31311883; PubMed Central PMCID:

905 PMCPMC6635531. 
906 24. Gago S, Serrano C, Alastruey-Izquierdo A, Cuesta I, Martin-Mazuelos E, Aller AI, et 907 al. Molecular identification, antifungal resistance and virulence of Cryptococcus neoformans 908 and Cryptococcus deneoformans isolated in Seville, Spain. Mycoses. 2017;60(1):40-50. doi: 909 10.1111/myc.12543. PubMed PMID: 27633849.

910 25. Desjardins CA, Giamberardino C, Sykes SM, Yu CH, Tenor JL, Chen Y, et al.

911 Population genomics and the evolution of virulence in the fungal pathogen Cryptococcus

912 neoformans. Genome Res. 2017;27(7):1207-19. doi: 10.1101/gr.218727.116. PubMed PMID:

913 28611159; PubMed Central PMCID: PMCPMC5495072.

914 26. Vanhove M, Beale MA, Rhodes J, Chanda D, Lakhi S, Kwenda G, et al. Genomic

915 epidemiology of Cryptococcus yeasts identifies adaptation to environmental niches

916 underpinning infection across an African HIV/AIDS cohort. Mol Ecol. 2017;26(7):1991-

917 2005. doi: 10.1111/mec.13891. PubMed PMID: 27862555; PubMed Central PMCID:

918 PMCPMC5412878.

919 27. Zaragoza O. Multiple Disguises for the Same Party: The Concepts of Morphogenesis

920 and Phenotypic Variations in Cryptococcus neoformans. Front Microbiol. 2011;2:181. doi:

921 10.3389/fmicb.2011.00181. PubMed PMID: 21922016; PubMed Central PMCID:

922 PMCPMC3167222.

923 28. Alanio A, Vernel-Pauillac F, Sturny-Leclere A, Dromer F. Cryptococcus neoformans

924 host adaptation: toward biological evidence of dormancy. mBio. 2015;6(2). doi:

925 10.1128/mBio.02580-14. PubMed PMID: 25827423; PubMed Central PMCID:

926 PMCPMC4453510.

927 29. Trevijano-Contador N, de Oliveira HC, García-Rodas R, Rossi SA, Llorente I,

928 Zaballos Á, et al. Cryptococcus neoformans can form titan-like cells in vitro in response to

929 multiple signals that require the activation of several transduction pathways. PLoS Pathog.

930 2018;14(5):e1007007. doi: 10.1371/journal.ppat.1007007.

931 30. Choi J, Vogl AW, Kronstad JW. Regulated expression of cyclic AMP-dependent

932 protein kinase A reveals an influence on cell size and the secretion of virulence factors in

933 Cryptococcus neoformans. Mol Microbiol. 2012;85(4):700-15. doi: 10.1111/j.1365-

934 2958.2012.08134.x. PubMed PMID: 22717009.

935 31. Hommel B, Mukaremera L, Cordero RJB, Coelho C, Desjardins CA, Sturny-Leclere

936 A, et al. Titan cells formation in Cryptococcus neoformans is finely tuned by environmental

937 conditions and modulated by positive and negative genetic regulators. PLoS Pathog.

938 2018;14(5):e1006982. doi: 10.1371/journal.ppat.1006982. PubMed PMID: 29775480;

939 PubMed Central PMCID: PMCPMC5959062.

940 32. Dylag M, Colon-Reyes RJ, Kozubowski L. Titan cell formation is unique to

941 Cryptococcus species complex. Virulence. 2020;11(1):719-29. doi:

942 10.1080/21505594.2020.1772657. PubMed PMID: 32498590.

943 33. Molloy SF, Kanyama C, Heyderman RS, Loyse A, Kouanfack C, Chanda D, et al.

944 Antifungal Combinations for Treatment of Cryptococcal Meningitis in Africa. N Engl J Med.

945 2018;378(11):1004-17. doi: 10.1056/NEJMoa1710922. PubMed PMID: 29539274.

946 34. Zhou X, Ballou ER. The Cryptococcus neoformans Titan Cell: From In Vivo

947 Phenomenon to In Vitro Model. Current Clinical Microbiology Reports. 2018;5(4):252-60.

948 doi: 10.1007/s40588-018-0107-9.

949 35. Mylonakis E, Moreno R, El Khoury JB, Idnurm A, Heitman J, Calderwood SB, et al.

950 Galleria mellonella as a model system to study Cryptococcus neoformans pathogenesis.

951 Infect Immun. 2005;73(7):3842-50. doi: 10.1128/IAI.73.7.3842-3850.2005. PubMed PMID:

952 15972469; PubMed Central PMCID: PMCPMC1168598.

953 36. Garcia-Rodas R, Casadevall A, Rodriguez-Tudela JL, Cuenca-Estrella M, Zaragoza O.

954 Cryptococcus neoformans capsular enlargement and cellular gigantism during Galleria 
955 mellonella infection. PLoS One. 2011;6(9):e24485. doi: 10.1371/journal.pone.0024485.

956 PubMed PMID: 21915338; PubMed Central PMCID: PMCPMC3168503.

957 37. Mylonakis E, Moreno R, El Khoury JB, Idnurm A, Heitman J, Calderwood SB, et al.

958 Galleria mellonella as a model system to study Cryptococcus neoformans pathogenesis.

959 Infection and Immunity. 2005;73(7):3842-50. doi: 10.1128/IAI.73.7.3842-3850.2005.

960 38. Erwig LP, Gow NA. Interactions of fungal pathogens with phagocytes. Nat Rev

961 Microbiol. 2016;14(3):163-76. doi: 10.1038/nrmicro.2015.21. PubMed PMID: 26853116.

962 39. Probert M, Zhou X, Goodall M, Johnston SA, Bielska E, Ballou ER, et al. A

963 Glucuronoxylomannan Epitope Exhibits Serotype-Specific Accessibility and Redistributes

964 towards the Capsule Surface during Titanization of the Fungal Pathogen <span

965 class="named-content genus-species" id="named-content-1">Cryptococcus

966 neoformans </span>. Infection and Immunity. 2019;87.

967 40. Owen DM, Rentero C, Magenau A, Abu-Siniyeh A, Gaus K. Quantitative imaging of

968 membrane lipid order in cells and organisms. Nature Protocols. 2012;7(1):24-35. doi:

969 10.1038/nprot.2011.419.

970 41. Delobel P, Tesniere C. A simple FCM method to avoid misinterpretation in

971 Saccharomyces cerevisiae cell cycle assessment between G0 and sub-G1. PLoS One.

972 2014;9(1):e84645. doi: 10.1371/journal.pone.0084645. PubMed PMID: 24392149; PubMed

973 Central PMCID: PMCPMC3879310.

974 42. Zhang J, Martinez-Gomez K, Heinzle E, Wahl SA. Metabolic switches from

975 quiescence to growth in synchronized Saccharomyces cerevisiae. Metabolomics.

976 2019;15(9):121. doi: 10.1007/s11306-019-1584-4. PubMed PMID: 31468142; PubMed

977 Central PMCID: PMCPMC6715666.

978 43. Zafar H, Altamirano S, Ballou ER, Nielsen K. A titanic drug resistance threat in

979 Cryptococcus neoformans. Curr Opin Microbiol. 2019;52:158-64. doi:

980 10.1016/j.mib.2019.11.001. PubMed PMID: 31765991.

981 44. Evans RJ, Li Z, Hughes WS, Djordjevic JT, Nielsen K, May RC. Cryptococcal

982 phospholipase B1 is required for intracellular proliferation and control of titan cell

983 morphology during macrophage infection. Infect Immun. 2015;83(4):1296-304. doi:

984 10.1128/IAI.03104-14. PubMed PMID: 25605772; PubMed Central PMCID:

985 PMCPMC4363446.

986 45. Robertson EJ, Najjuka G, Rolfes MA, Akampurira A, Jain N, Anantharanjit J, et al.

987 Cryptococcus neoformans ex vivo capsule size is associated with intracranial pressure and

988 host immune response in HIV-associated cryptococcal meningitis. J Infect Dis.

989 2014;209(1):74-82. doi: 10.1093/infdis/jit435. PubMed PMID: 23945372; PubMed Central

990 PMCID: PMCPMC3864387.

991 46. Hommel B, Mukaremera L, Cordero RJB, Desjardins CA, Sturny-Leclere A, Perfect

992 JR ea. Identification of environmental and genetic factors important for Cryptococcus

993 neoformans titan cell formation using new in vitro inducing conditions. PLoS Pathog. 2018.

994 47. Fernandes KE, Dwyer C, Campbell LT, Carter DA. Species in the Cryptococcus gattii

995 Complex Differ in Capsule and Cell Size following Growth under Capsule-Inducing

996 Conditions. mSphere. 2016;1(6). doi: 10.1128/mSphere.00350-16. PubMed PMID: 28066814;

997 PubMed Central PMCID: PMCPMC5196034.

998 48. Aslanyan L, Ekhar VV, DeLeon-Rodriguez CM, Martinez LR. Capsular specific IgM

999 enhances complement-mediated phagocytosis and killing of Cryptococcus neoformans by

1000 methamphetamine-treated J774.16 macrophage-like cells. Int Immunopharmacol.

1001 2017;49:77-84. Epub 2017/05/25. doi: 10.1016/j.intimp.2017.05.024. PubMed PMID:

100228551495.

1003 49. Trevijano-Contador N, Pianalto KM, Nichols CB, Zaragoza O, Alspaugh JA, Pirofski

1004 L-a. Human IgM Inhibits the Formation of Titan-Like Cells in <span class="named-content 
1005 genus-species" id="named-content-1">Cryptococcus neoformans $</$ span $>$. Infection and

1006 Immunity. 2020;88.

1007 50. Litvack ML, Post M, Palaniyar N. IgM Promotes the Clearance of Small Particles and

1008 Apoptotic Microparticles by Macrophages. PLOS ONE. 2011;6(3):e17223. doi:

1009 10.1371/journal.pone.0017223.

1010 51. Semighini CP, Averette AF, Perfect JR, Heitman J. Deletion of Cryptococcus

1011 neoformans AIF ortholog promotes chromosome aneuploidy and fluconazole-resistance in a

1012 metacaspase-independent manner. PLoS Pathogens. 2011;7(11):e1002364. doi:

1013 10.1371/journal.ppat.1002364.

1014 52. Gusa A, Williams JD, Cho JE, Averette AF, Sun S, Shouse EM, et al. Transposon

1015 mobilization in the human fungal pathogen Cryptococcus is mutagenic during infection and

1016 promotes drug resistance in vitro. Proc Natl Acad Sci U S A. 2020. doi:

1017 10.1073/pnas.2001451117. PubMed PMID: 32303657.

1018 53. Morrow CA, Lee IR, Chow EW, Ormerod KL, Goldinger A, Byrnes EJ, 3rd, et al. A

1019 unique chromosomal rearrangement in the Cryptococcus neoformans var. grubii type strain

1020 enhances key phenotypes associated with virulence. mBio. 2012;3(2). doi:

1021 10.1128/mBio.00310-11. PubMed PMID: 22375073; PubMed Central PMCID:

1022 PMCPMC3302566.

1023 54. Hickman MA, Zeng G, Forche A, Hirakawa MP, Abbey D, Harrison BD, et al. The

1024 'obligate diploid' Candida albicans forms mating-competent haploids. Nature.

1025 2013;494(7435):55-9. doi: 10.1038/nature11865. PubMed PMID: 23364695; PubMed

1026 Central PMCID: PMCPMC3583542.

1027 55. Todd RT, Wikoff TD, Forche A, Selmecki A. Genome plasticity in Candida albicans

1028 is driven by long repeat sequences. Elife. 2019;8. doi: 10.7554/eLife.45954. PubMed PMID:

1029 31172944; PubMed Central PMCID: PMCPMC6591007.

1030 56. Forche A, Abbey D, Pisithkul T, Weinzierl MA, Ringstrom T, Bruck D, et al. Stress

1031 alters rates and types of loss of heterozygosity in Candida albicans. mBio. 2011;2(4). doi:

1032 10.1128/mBio.00129-11. PubMed PMID: 21791579; PubMed Central PMCID:

1033 PMCPMC3143845.

1034 57. Forche A, Cromie G, Gerstein AC, Solis NV, Pisithkul T, Srifa W, et al. Rapid

1035 Phenotypic and Genotypic Diversification After Exposure to the Oral Host Niche in Candida

1036

1037

1038

1039

1040

1041 albicans. Genetics. 2018;209(3):725-41. doi: 10.1534/genetics.118.301019. PubMed PMID: 29724862; PubMed Central PMCID: PMCPMC6028260.

58. Ashton PM, Thanh LT, Trieu PH, Van Anh D, Trinh NM, Beardsley J, et al. Three phylogenetic groups have driven the recent population expansion of Cryptococcus neoformans. Nature communications. 2019;10(1):2035. doi: 10.1038/s41467-019-10092-5.

PubMed PMID: 31048698; PubMed Central PMCID: PMCPMC6497710.

1042 59. Litvintseva AP, Kestenbaum L, Vilgalys R, Mitchell TG. Comparative analysis of

1043 environmental and clinical populations of Cryptococcus neoformans. J Clin Microbiol.

1044 2005;43(2):556-64. doi: 10.1128/JCM.43.2.556-564.2005. PubMed PMID: 15695645;

1045 PubMed Central PMCID: PMCPMC548066.

1046 60. Kozubowski L, Yadav V, Chatterjee G, Sridhar S, Yamaguchi M, Kawamoto S, et al.

1047 Ordered kinetochore assembly in the human-pathogenic basidiomycetous yeast Cryptococcus

1048 neoformans. MBio. 2013;4(5):e00614-13. Epub 2013/10/03. doi: 10.1128/mBio.00614-13.

1049 PubMed PMID: 24085781; PubMed Central PMCID: PMC3791896.

1050 61. Smith LM, Dixon EF, May RC. The fungal pathogen Cryptococcus neoformans

1051 manipulates macrophage phagosome maturation. Cell Microbiol. 2015;17(5):702-13. Epub

1052 2014/11/15. doi: 10.1111/cmi.12394. PubMed PMID: 25394938. 
1053 62. Narra R, Maeda JM, Temba H, Mghamba J, Nyanga A, Greiner AL, et al. Notes from 1054 the Field: Ongoing Cholera Epidemic - Tanzania, 2015-2016. MMWR Morb Mortal Wkly 1055 Rep. 2017;66(6):177-8. doi: 10.15585/mmwr.mm6606a5. PubMed PMID: 28207686.

1056 63. Casadevall A, Cleare W, Feldmesser M, Glatman-Freedman A, Goldman DL, Kozel 1057 TR, et al. Characterization of a murine monoclonal antibody to Cryptococcus neoformans 1058 polysaccharide that is a candidate for human therapeutic studies. Antimicrob Agents 1059 Chemother. 1998;42(6):1437-46. PubMed PMID: 9624491; PubMed Central PMCID: 1060 PMCPMC105619.

1061 64. Gilbert AS, Seoane PI, Sephton-Clark P, Bojarczuk A, Hotham R, Giurisato E, et al. 1062 Vomocytosis of live pathogens from macrophages is regulated by the atypical MAP kinase 1063 ERK5. Sci Adv. 2017;3(8):e1700898. doi: 10.1126/sciadv.1700898. PubMed PMID: 1064 28835924; PubMed Central PMCID: PMCPMC5559206. 
A

T-H99

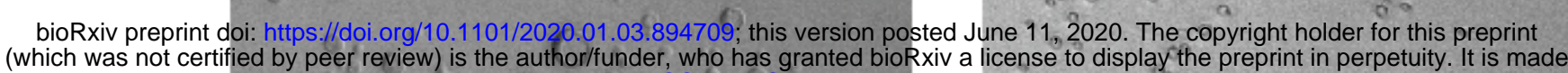
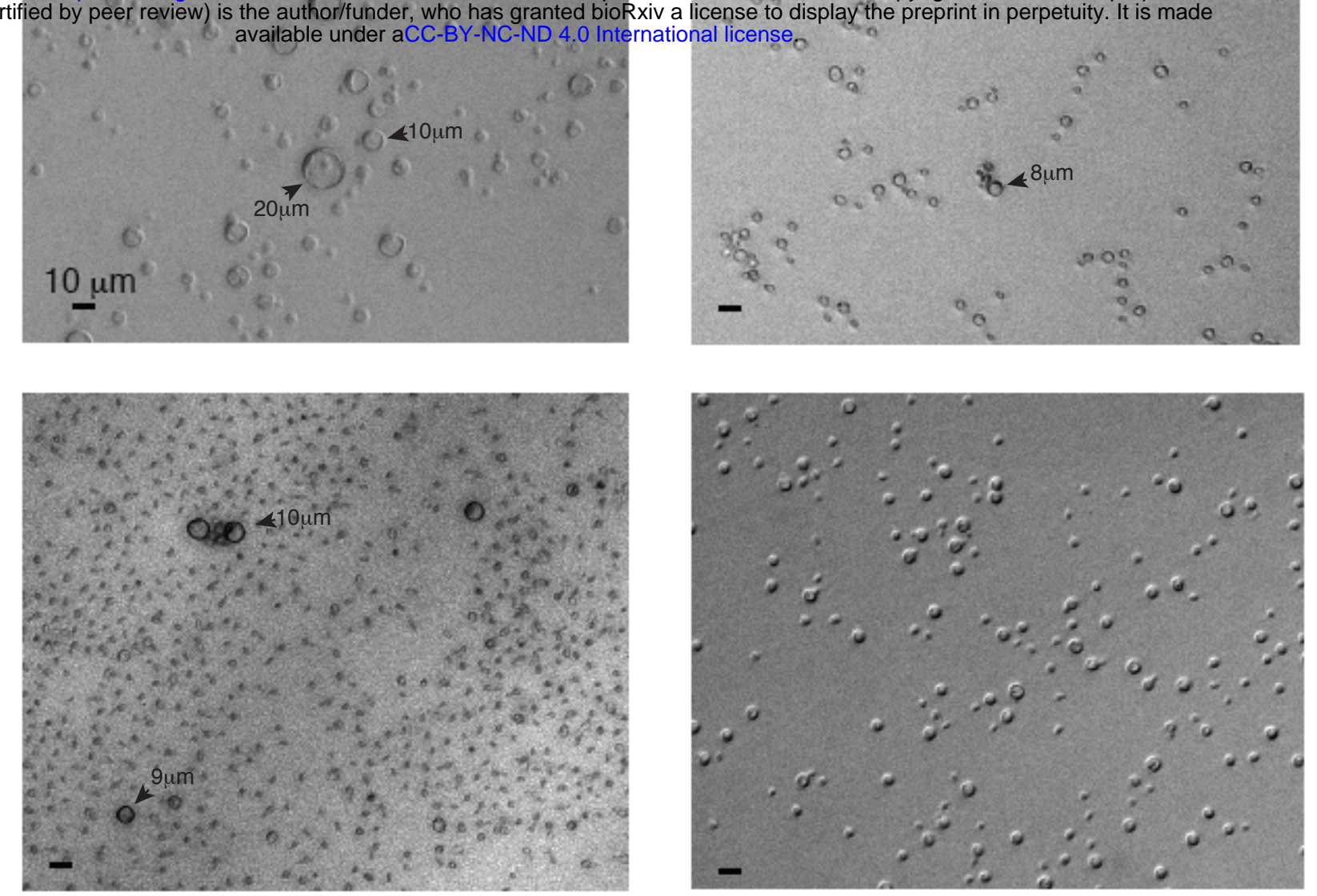

T-Zc8
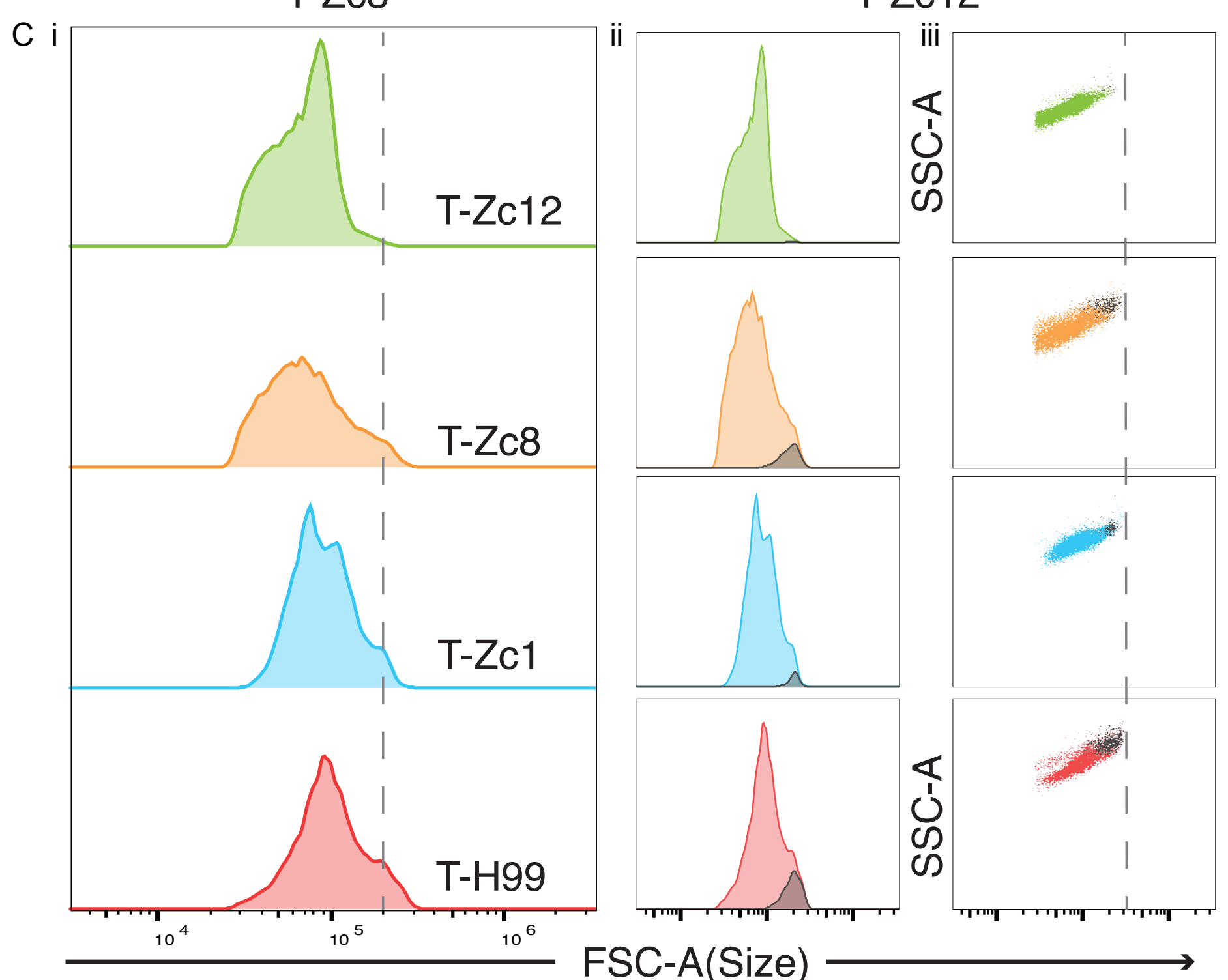

B
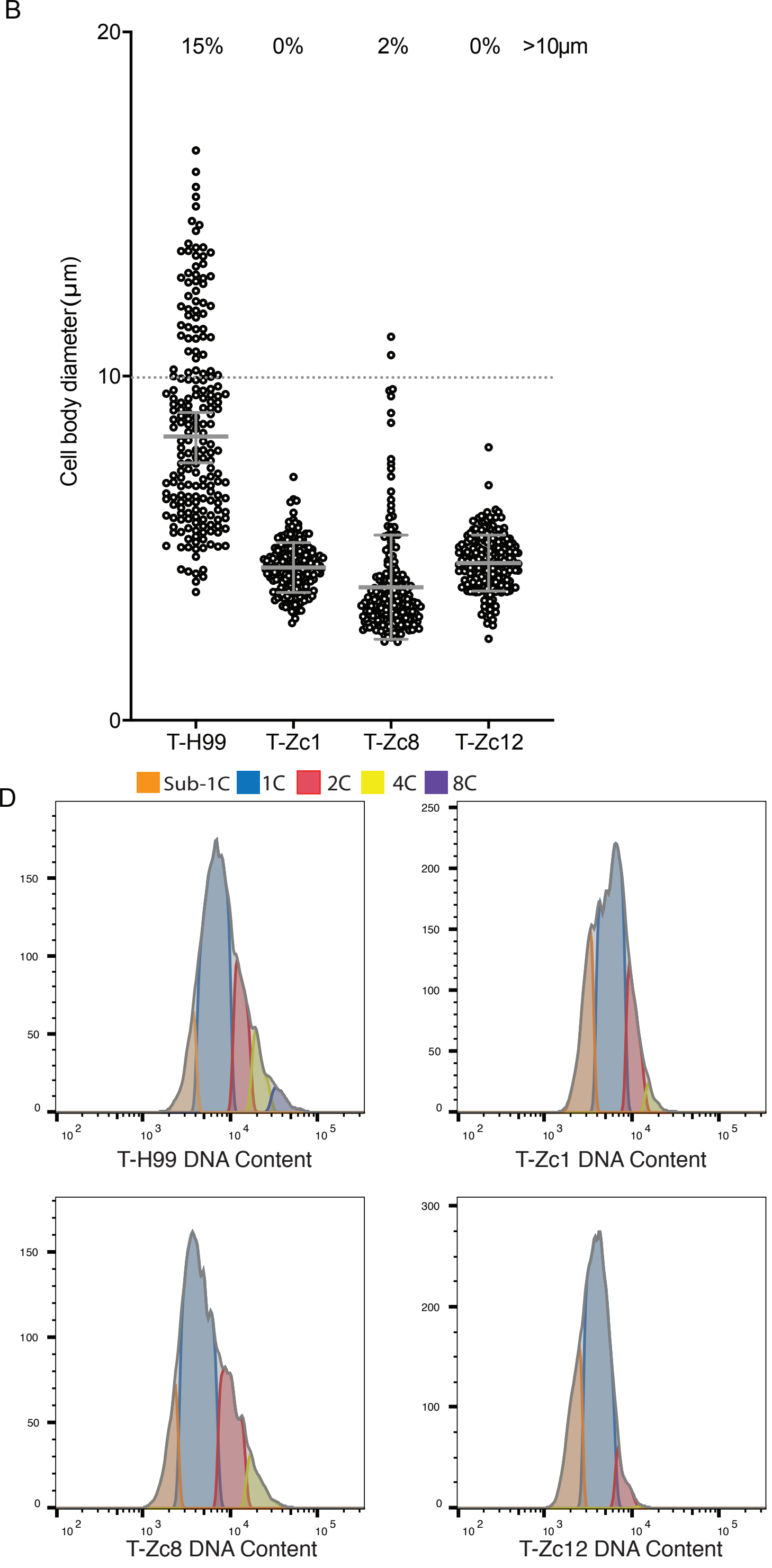
A

H99

Zc1

Zc8

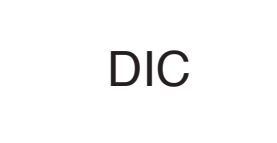

Mannan
(ConA)

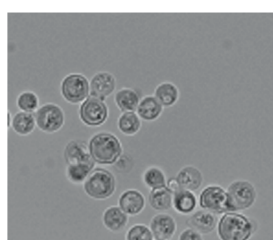

Chitosan (EosinY)

Chitin
(CFW)

Overlay
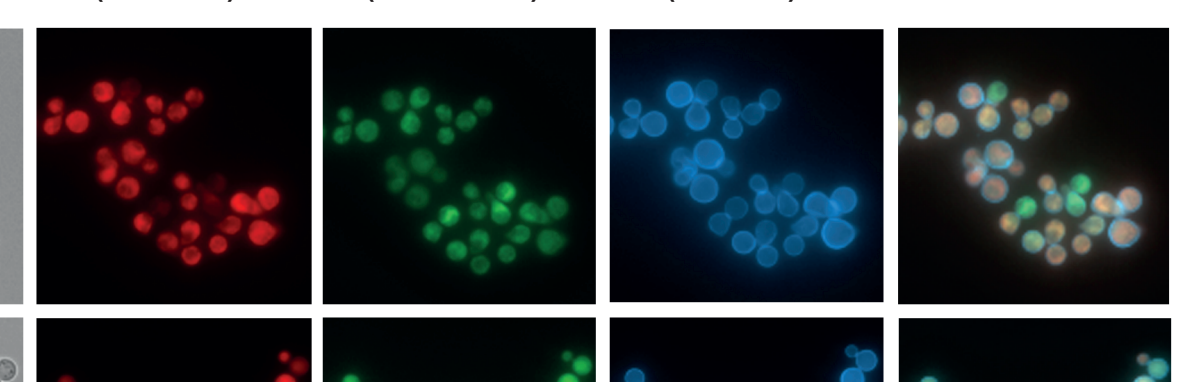

Zc12

T-H99

T-Zc1

T-Zc8

T-Zc12
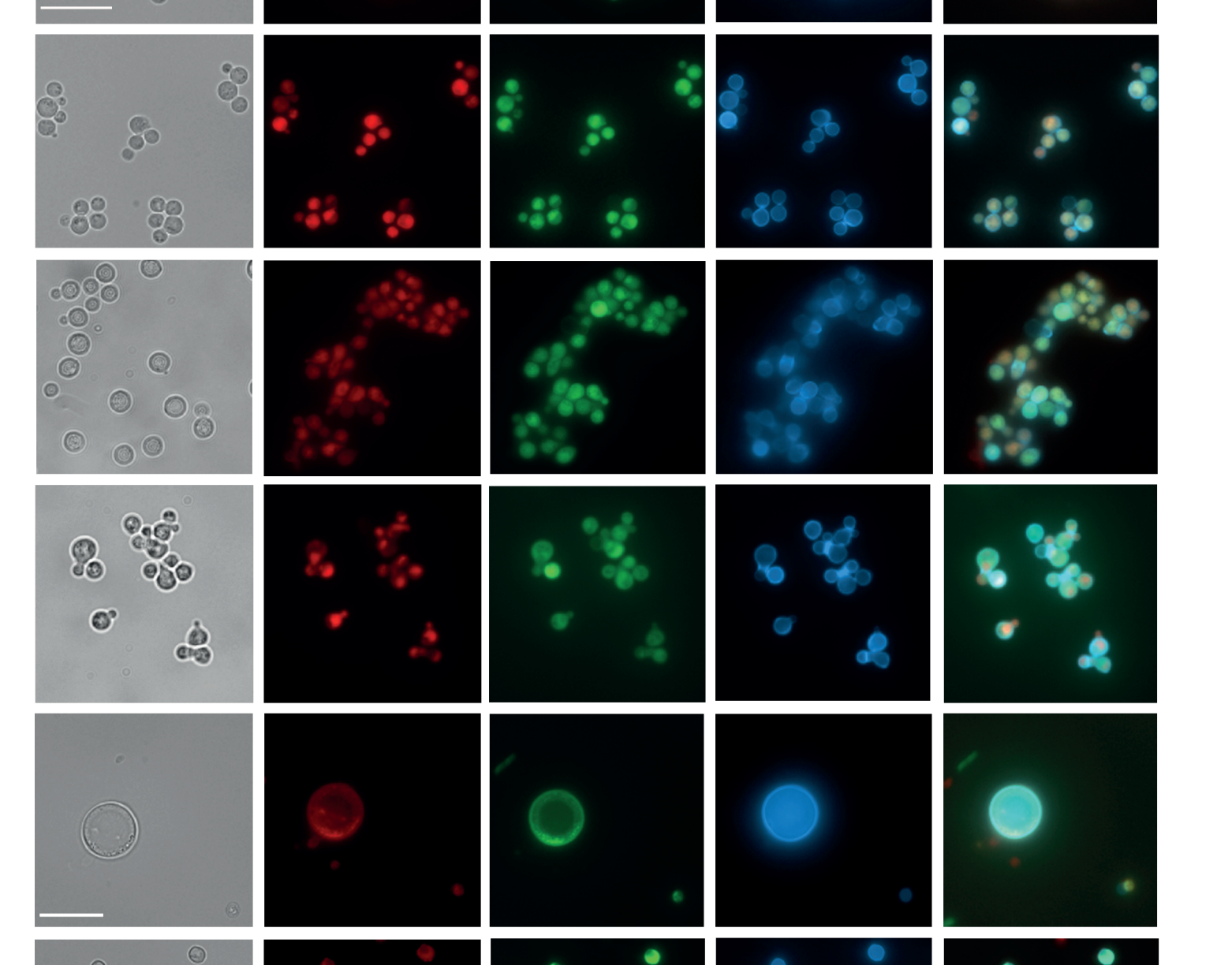

0
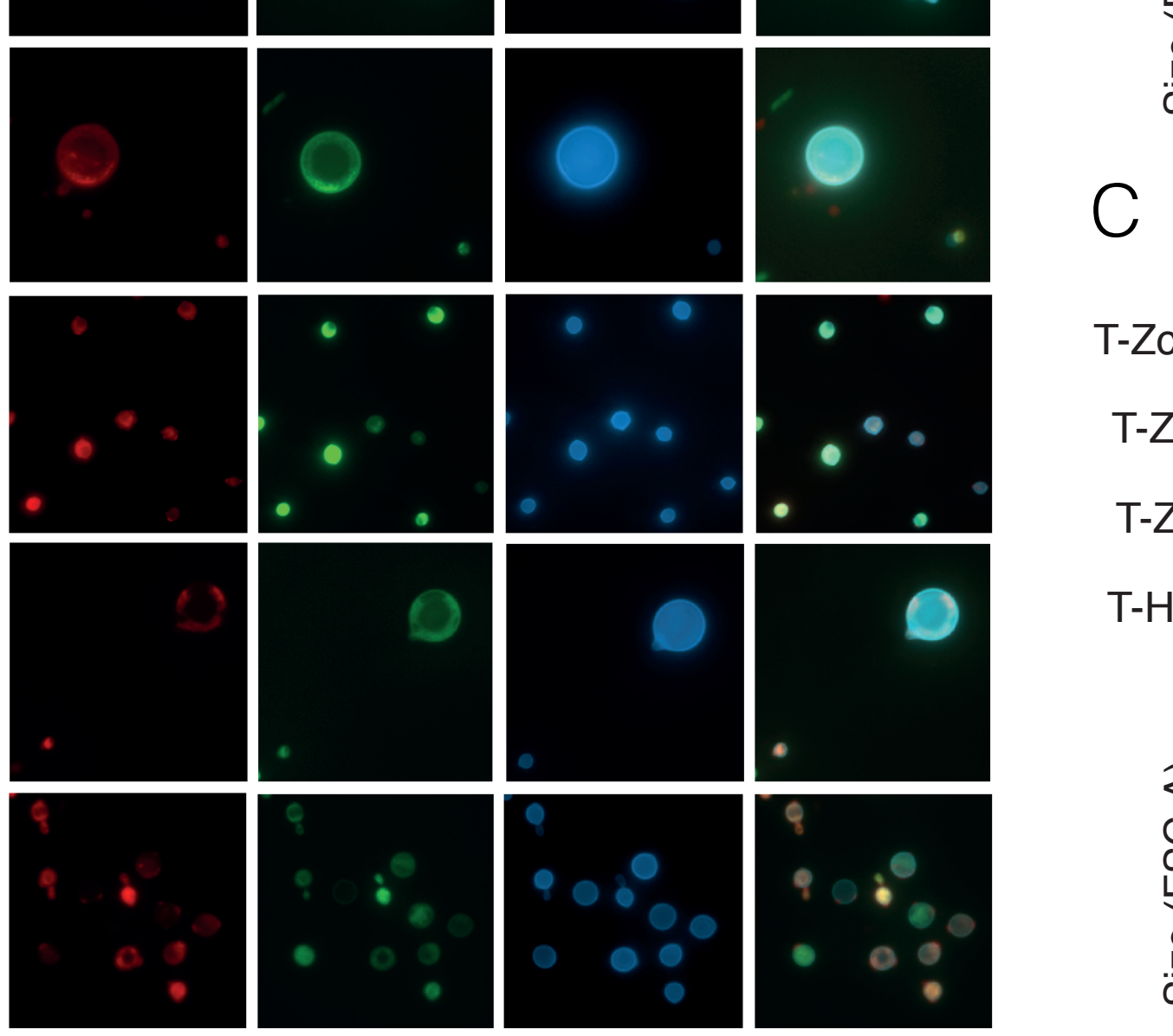

C

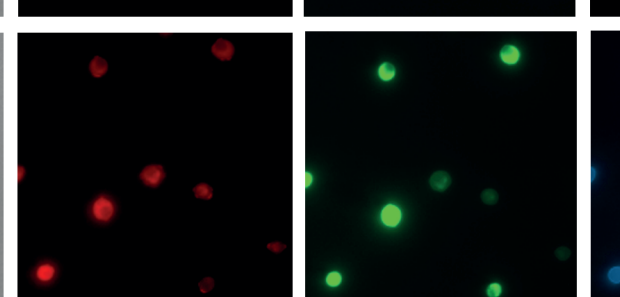

B

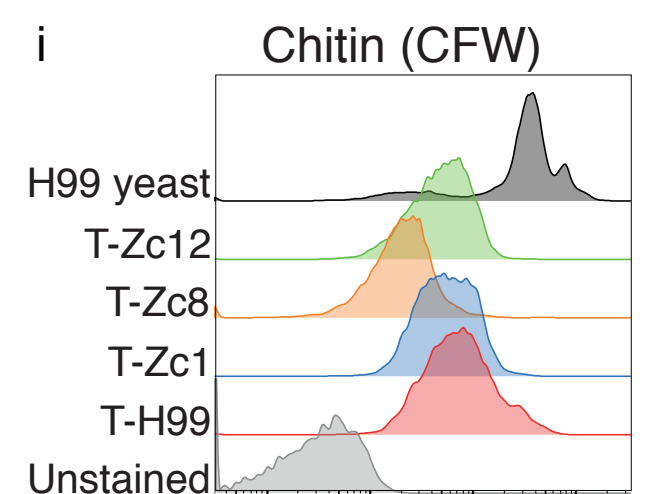

Mannan (ConA)

Chitosan (EosinY)
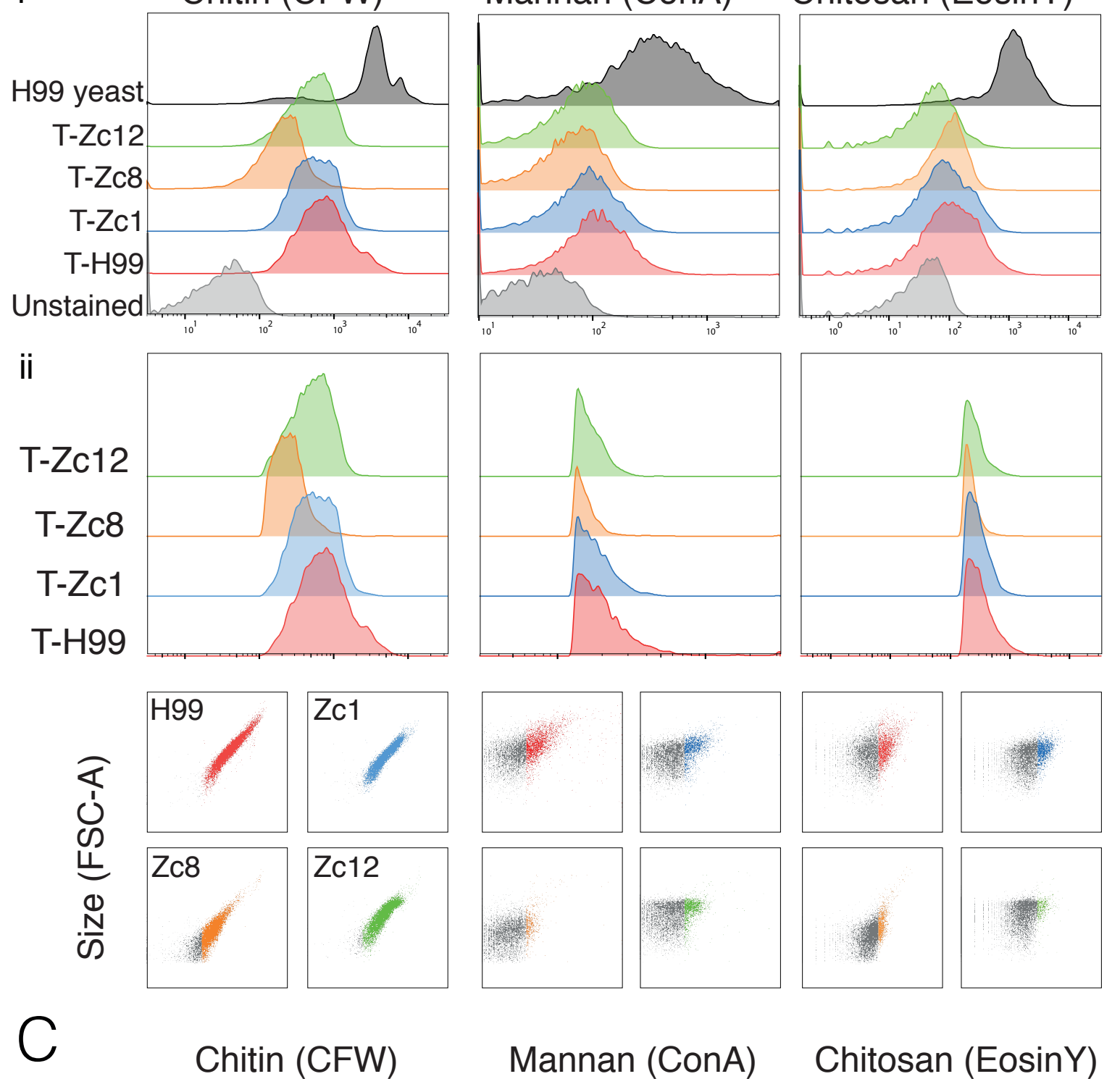

Mannan (ConA)

Chitosan (EosinY)

T-Zc12

T-Zc8

$\mathrm{T}-\mathrm{Zc1}$

T-H99
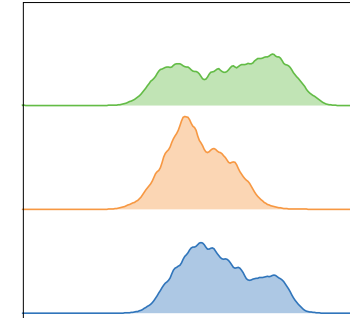

(1)
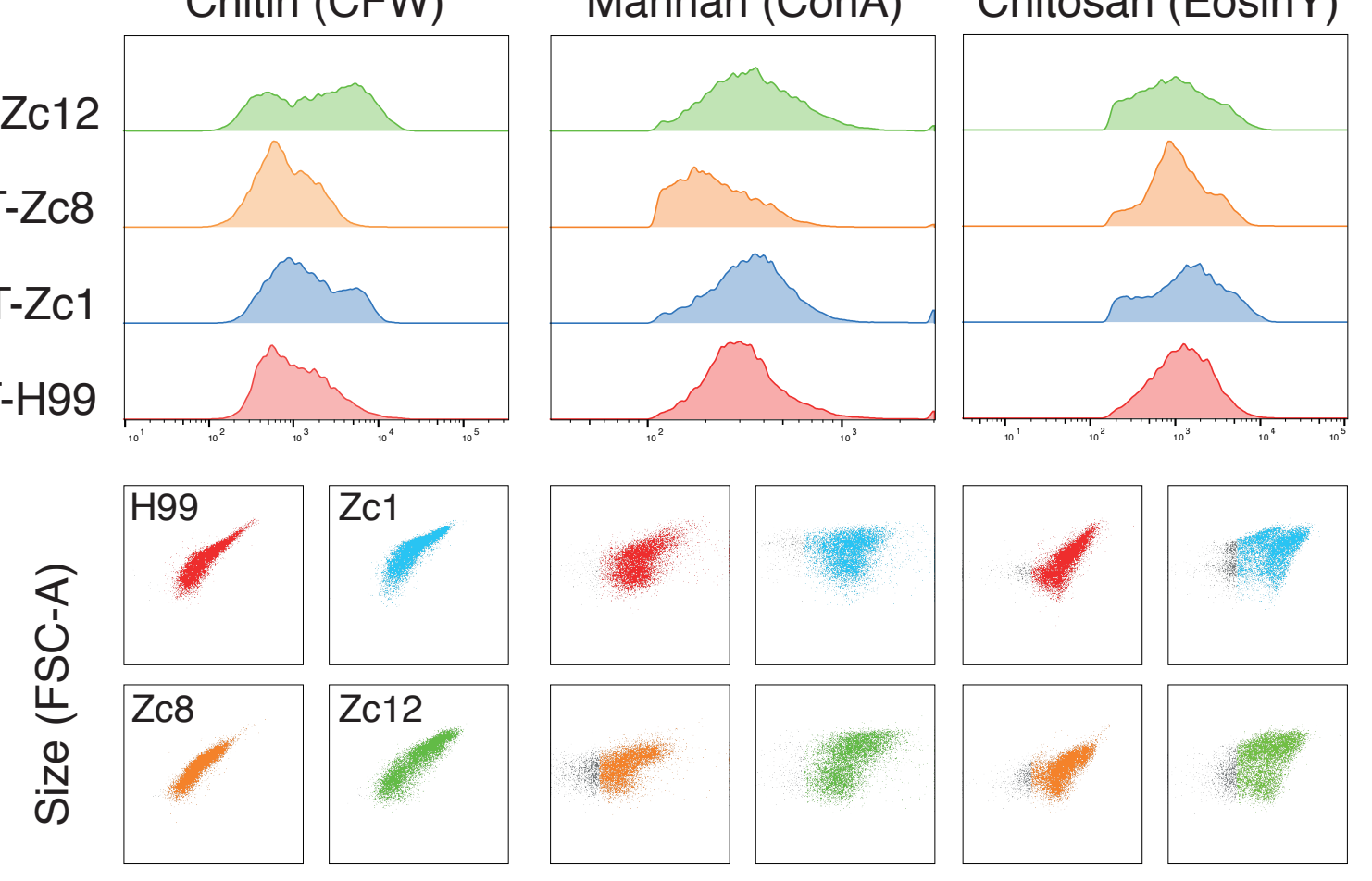


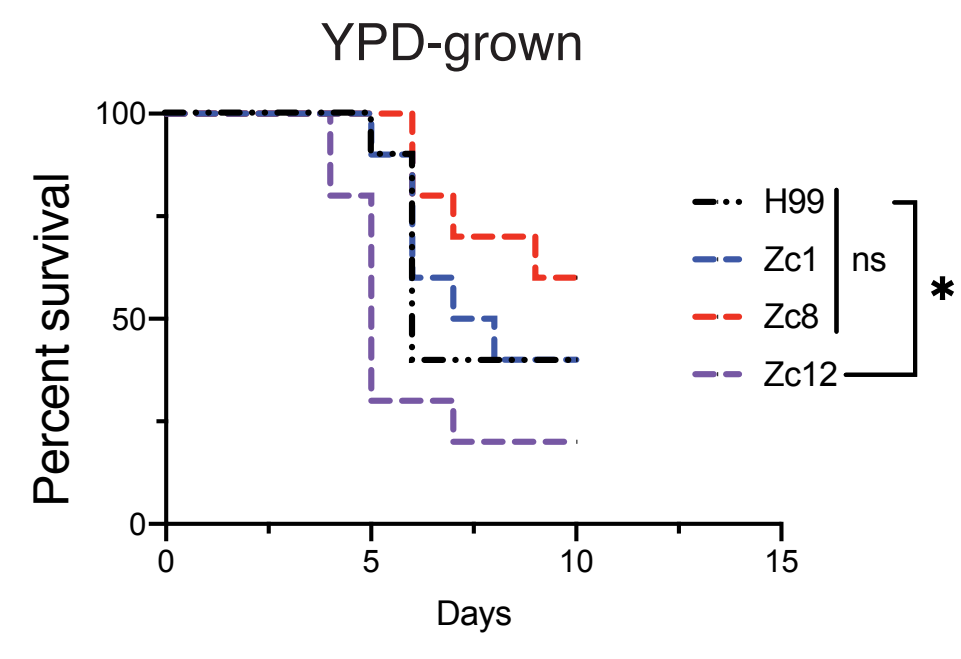

Induced

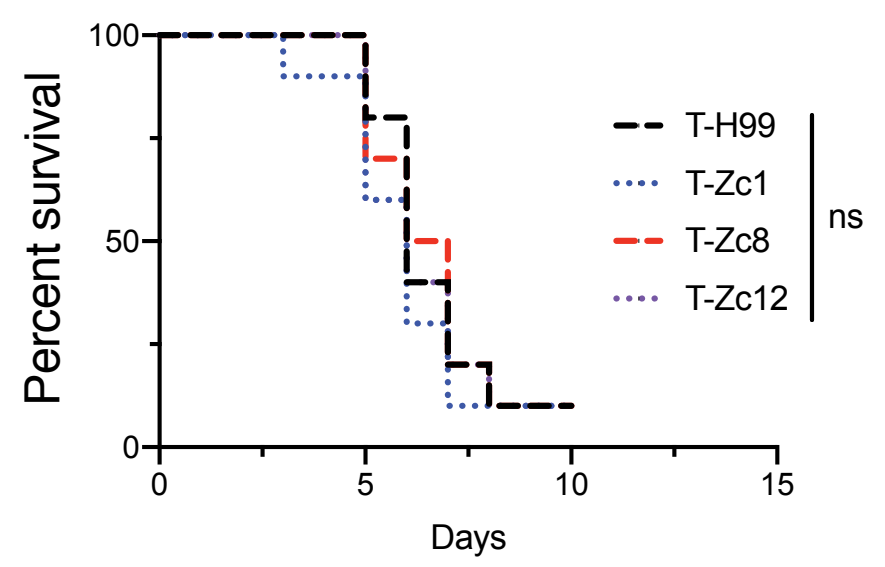

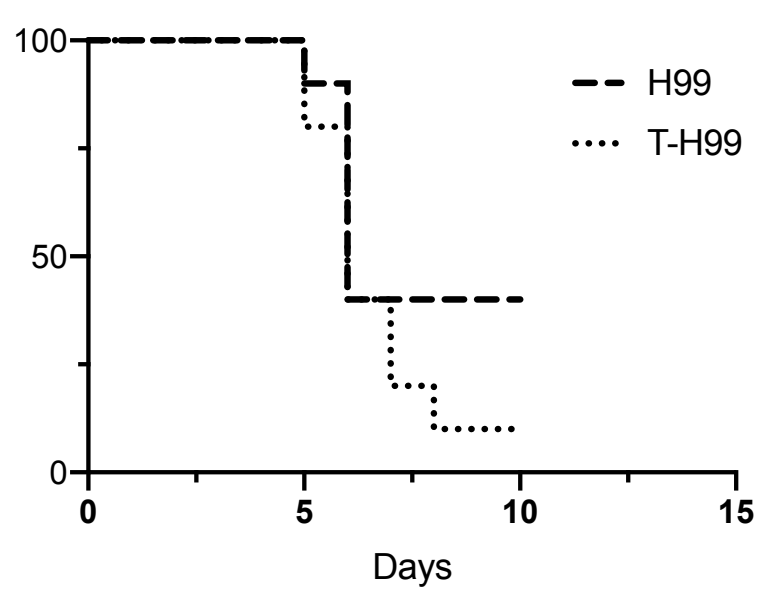
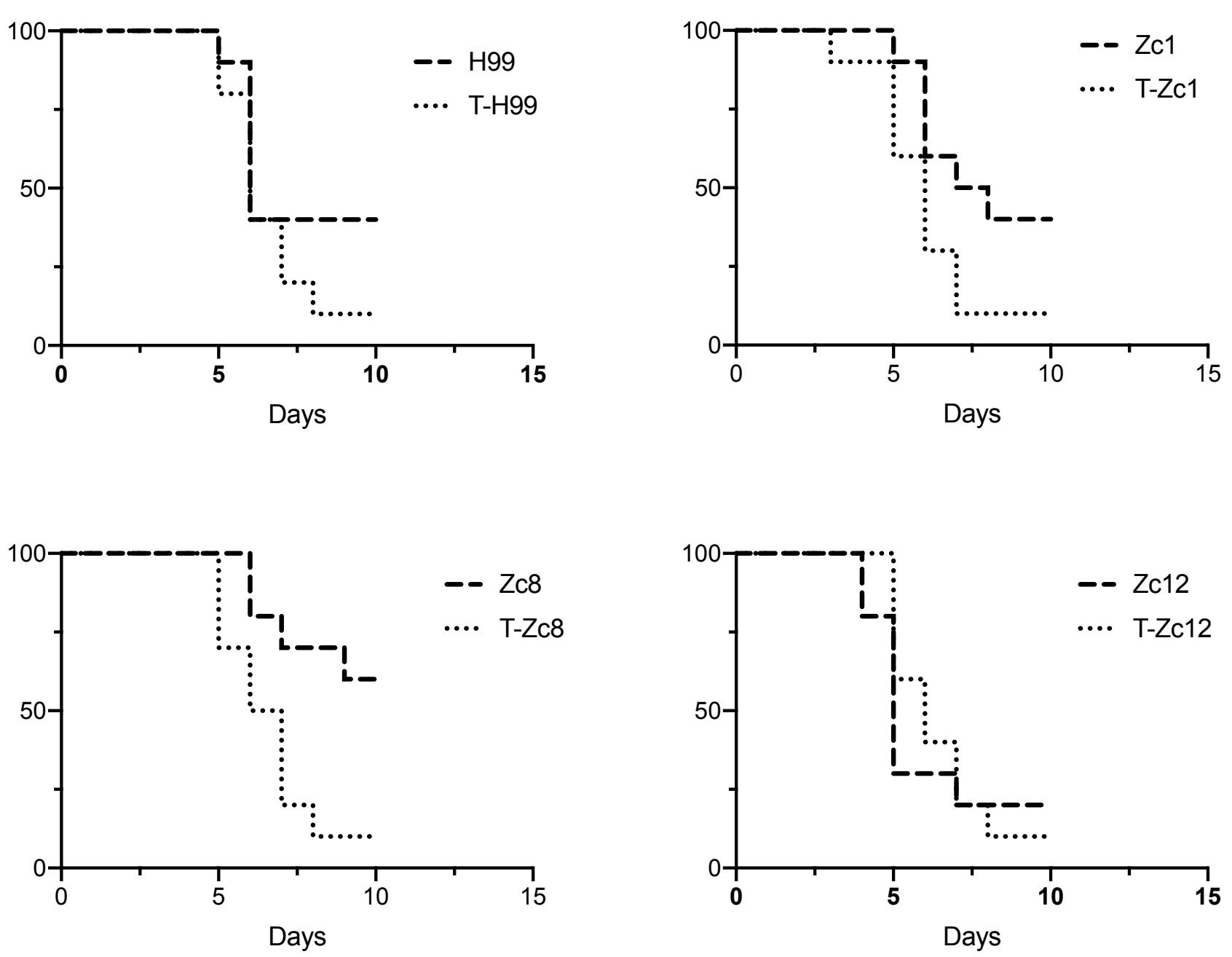

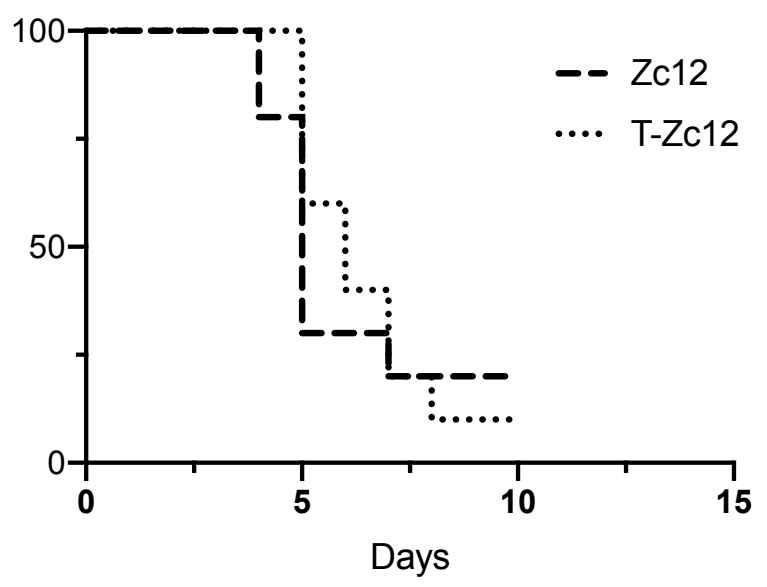




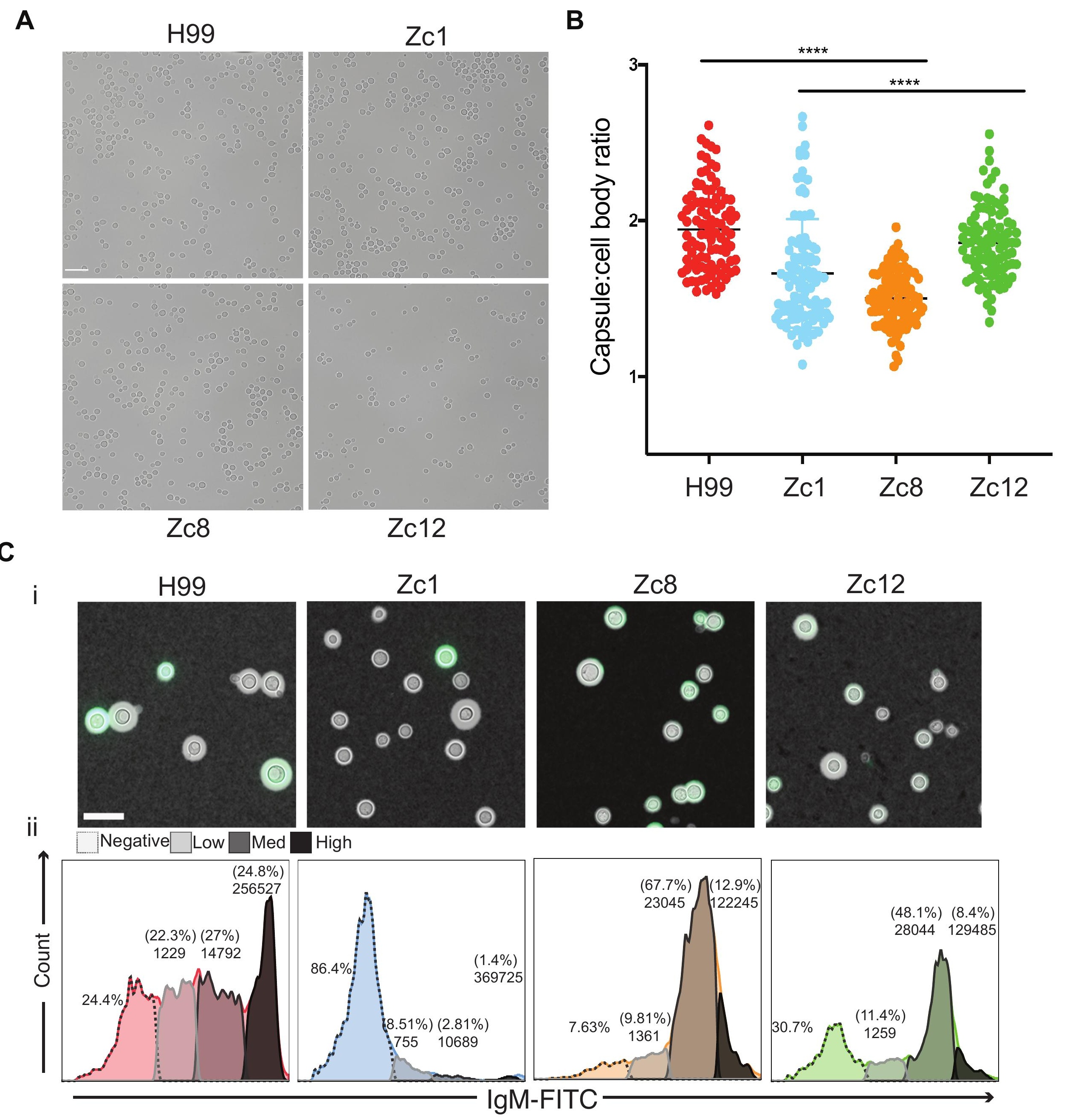



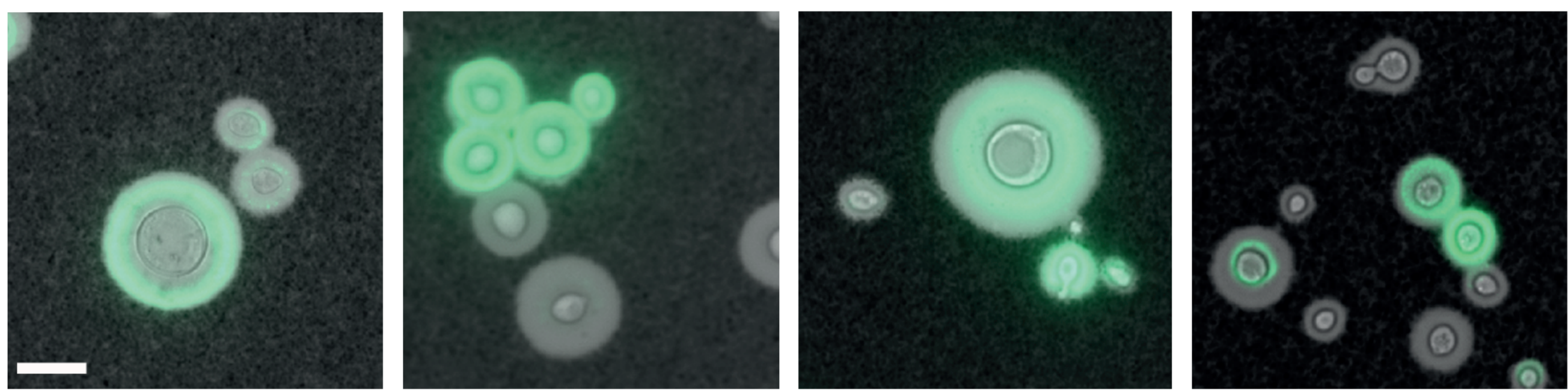

B

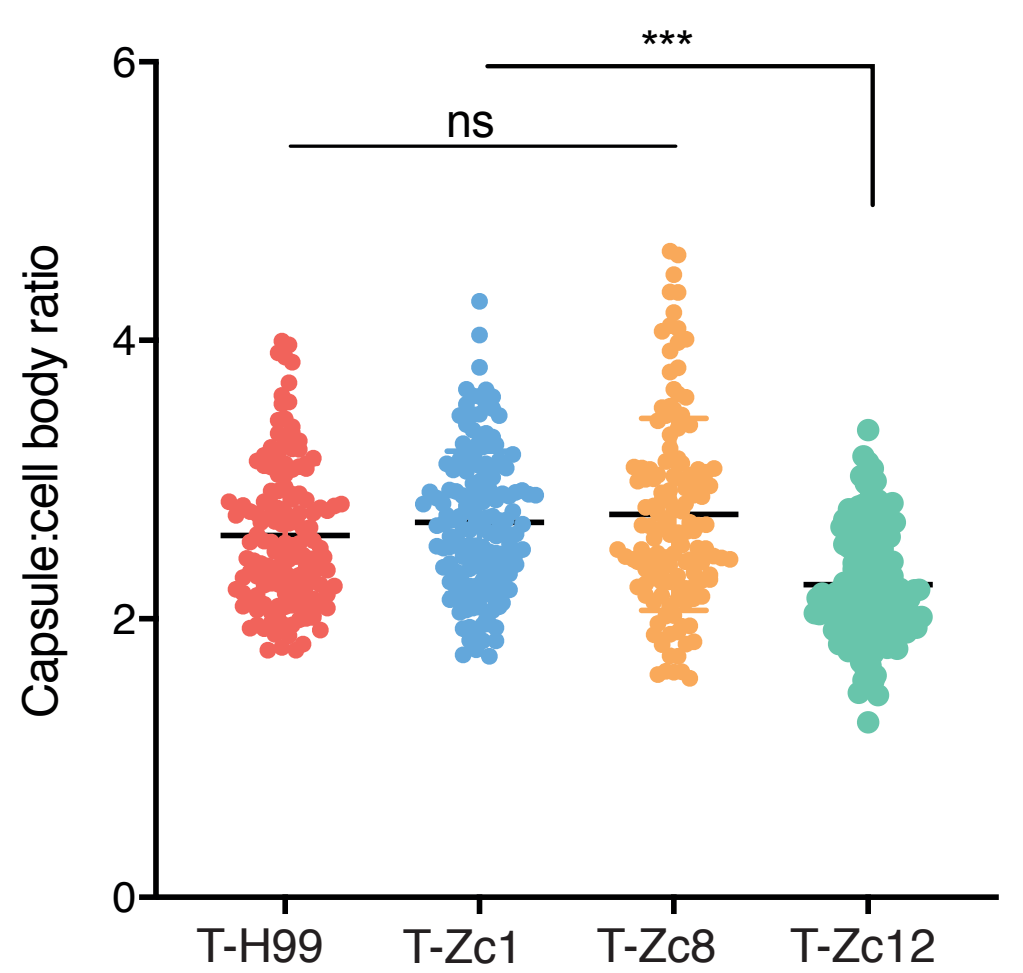

D

\begin{tabular}{cc|c|c|c|}
\multicolumn{1}{c}{} & \multicolumn{1}{c}{ T-H99 } & \multicolumn{1}{c}{ T-Zc1 } & \multicolumn{1}{c}{ T-Zc8 } & \multicolumn{1}{c}{ T-Zc12 } \\
\cline { 2 - 6 }$(\%$ Neg) & $(36.9)$ & $(63.1)$ & $(94.3)$ & $(39.9)$ \\
Low (\%) & $420(18.9)$ & $528(9.52)$ & $220(4.55)$ & $345(47.5)$ \\
Med (\%) & $1955(23.8)$ & $1693(24.6)$ & $1385(0.07)$ & $1134(8.78)$ \\
High (\%) & $5601(18.9)$ & $4533(1.33)$ & N/A & $5234(0.72)$ \\
\cline { 2 - 6 } & & &
\end{tabular}

C i

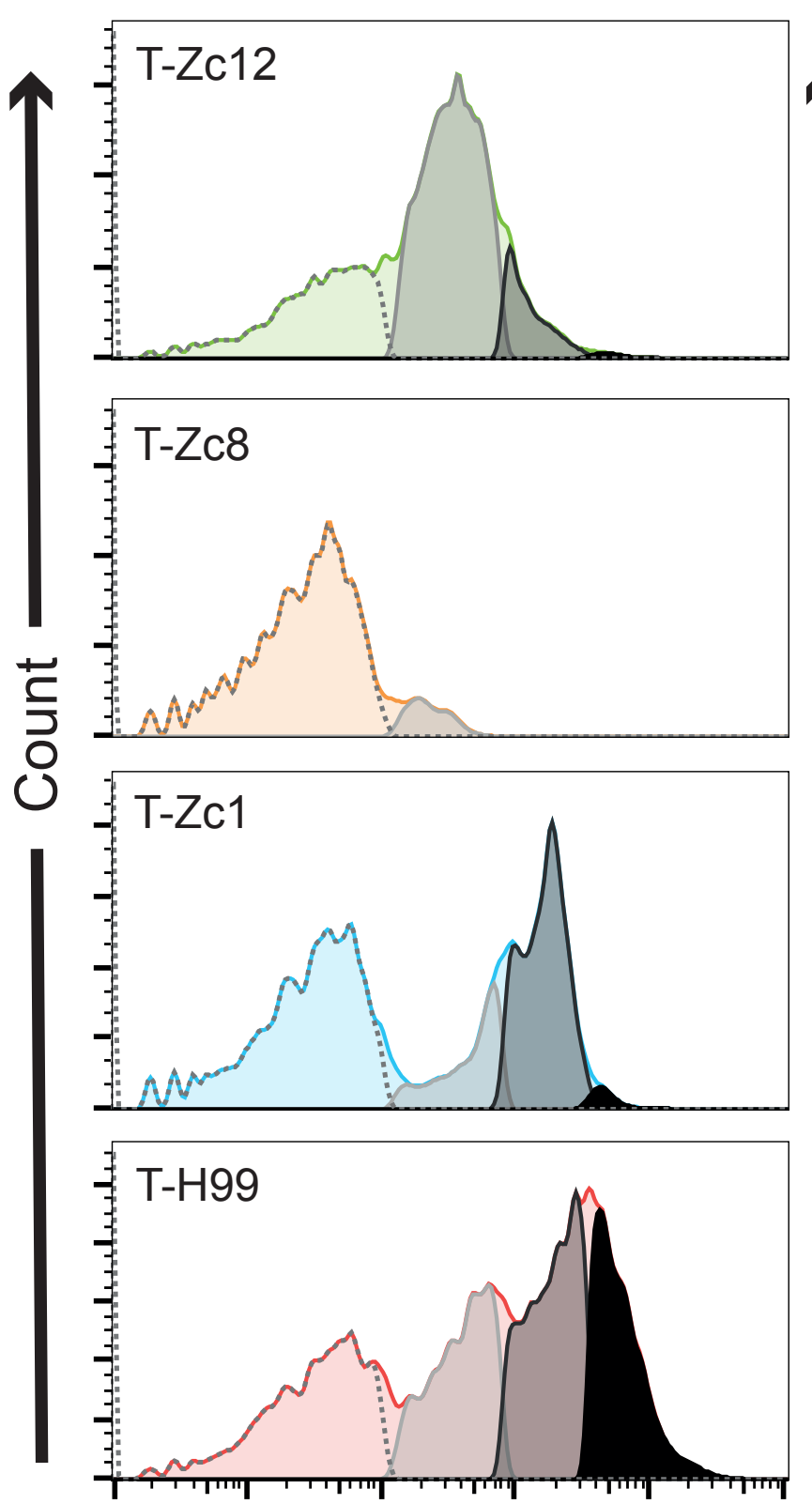

ii

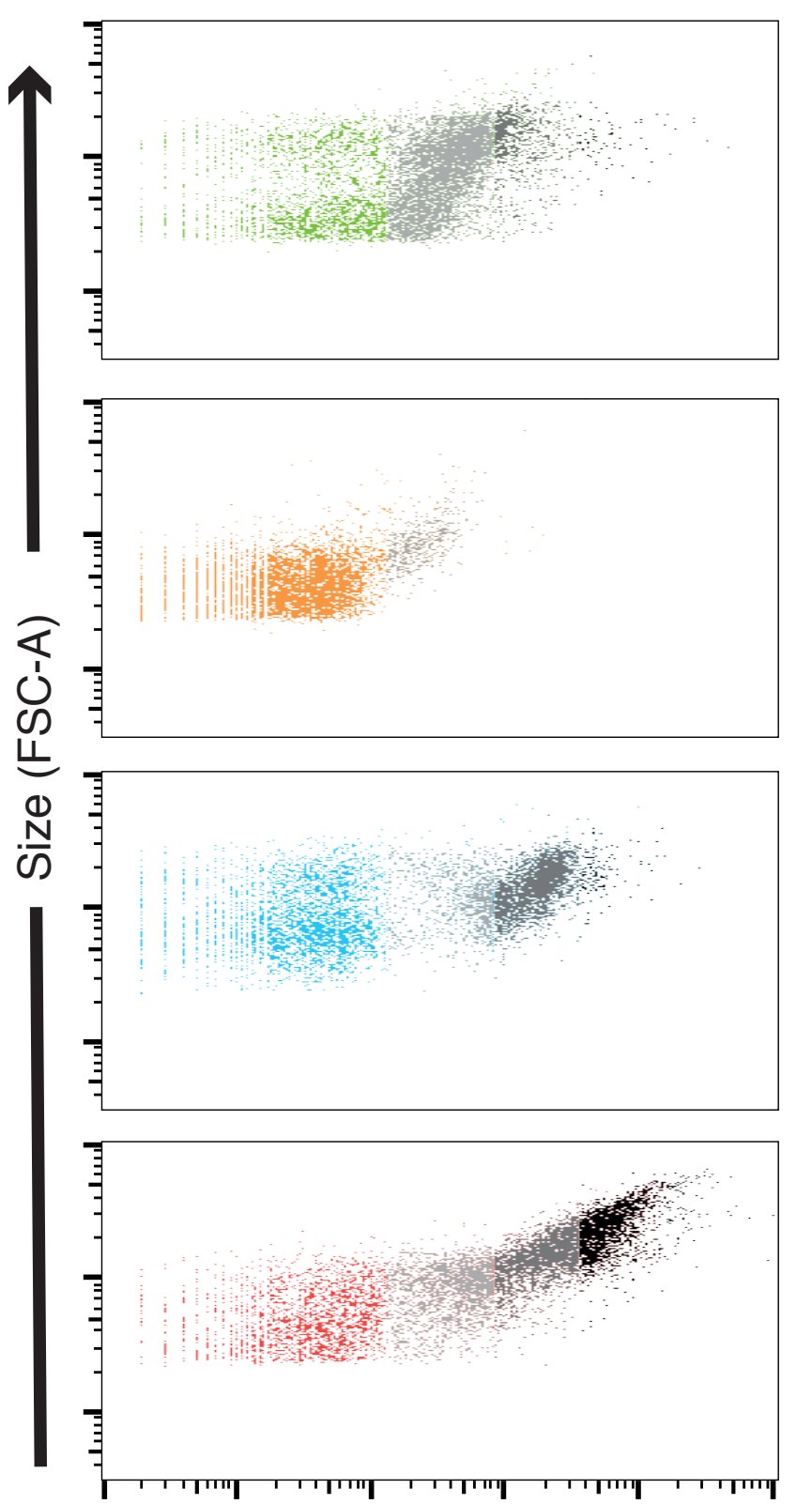



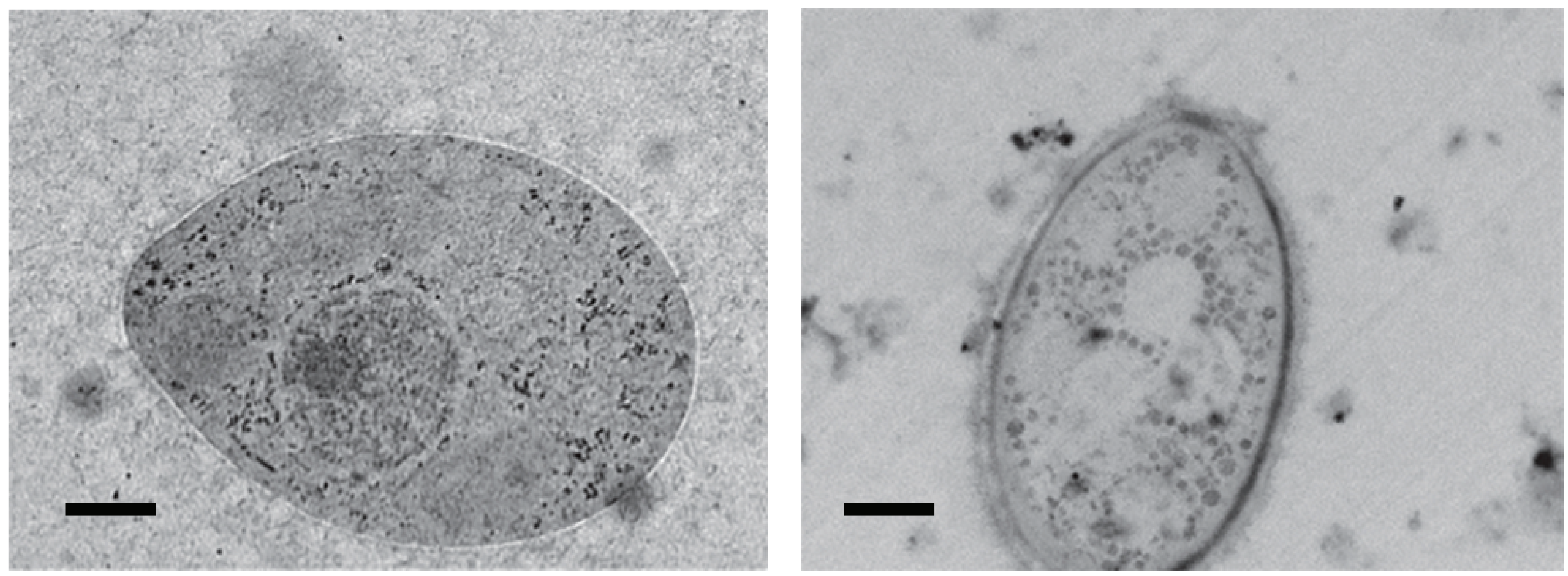

B

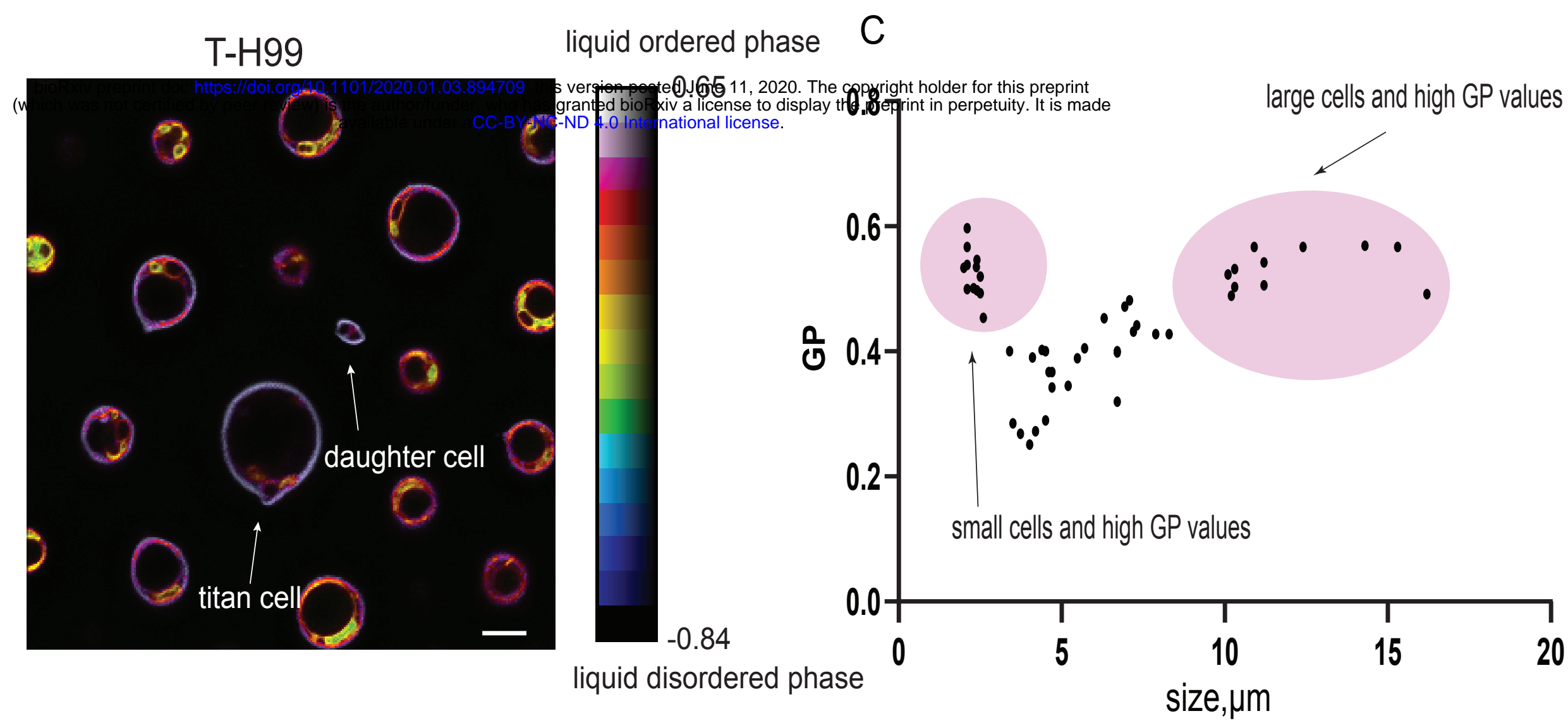

D

E

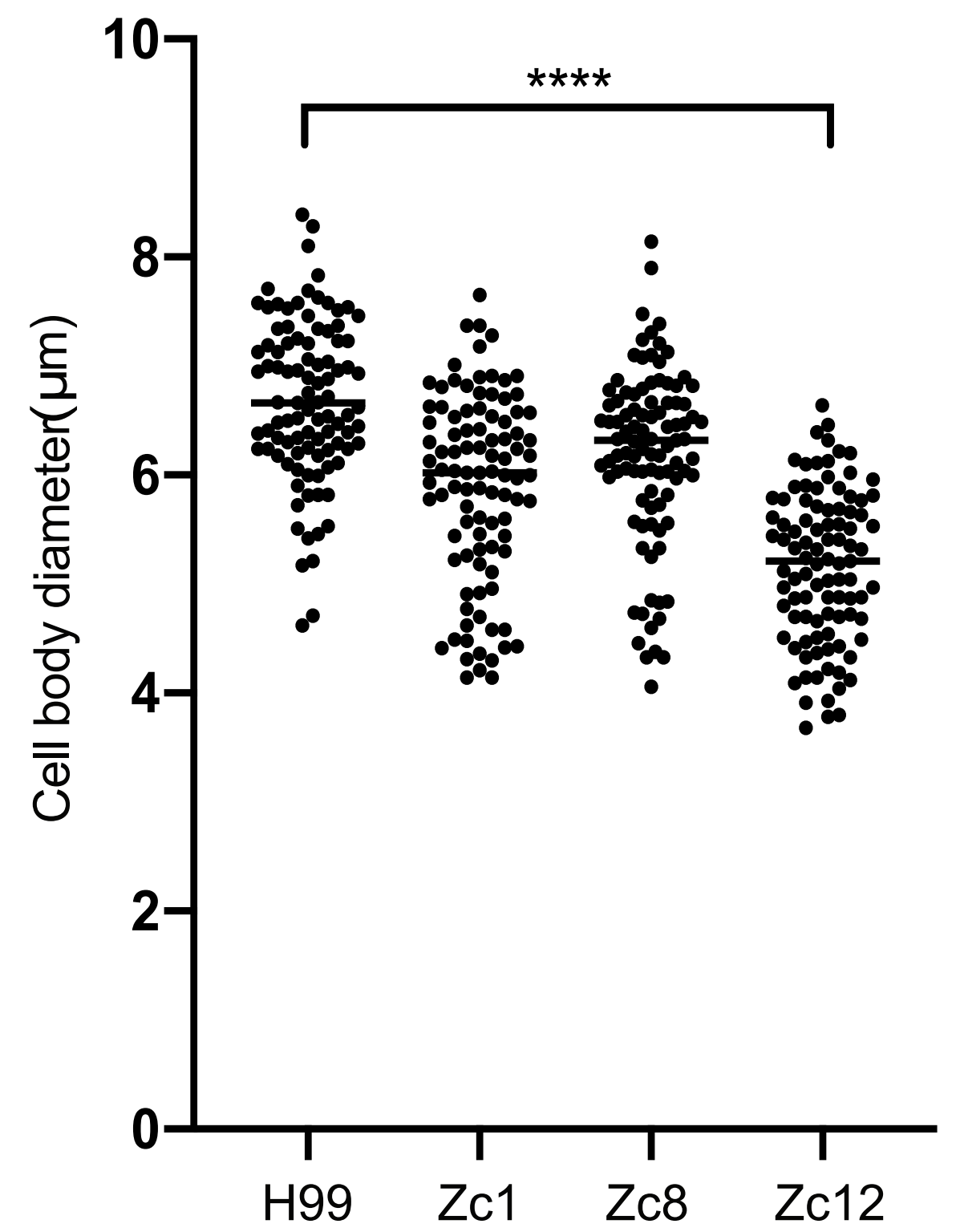

Sub-1C $1 C \quad 2 C$

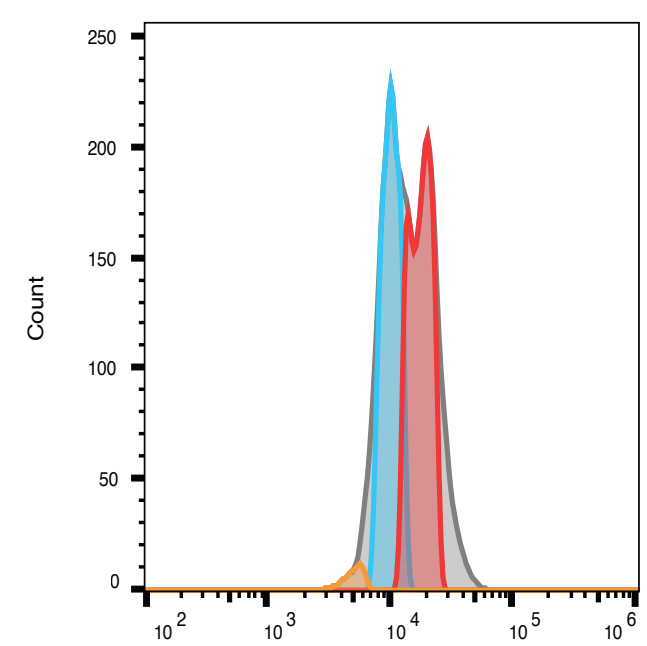

H99 DNA content

YPD-grown yeast

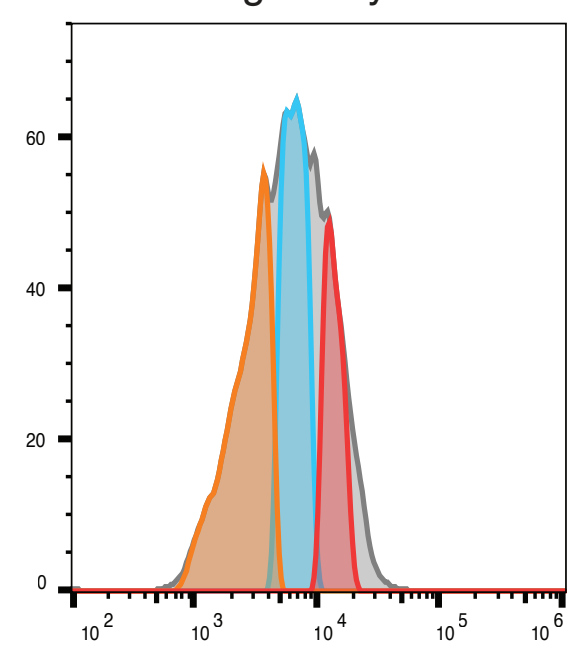

Zc1 DNA content
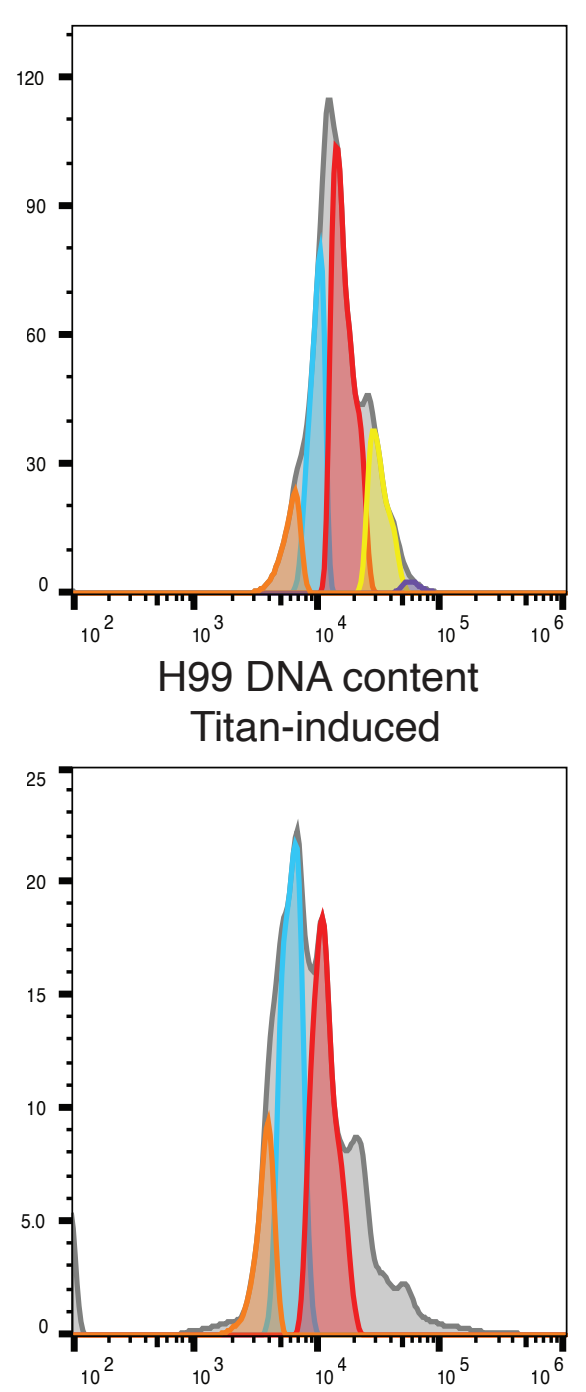

Zc8 DNA content

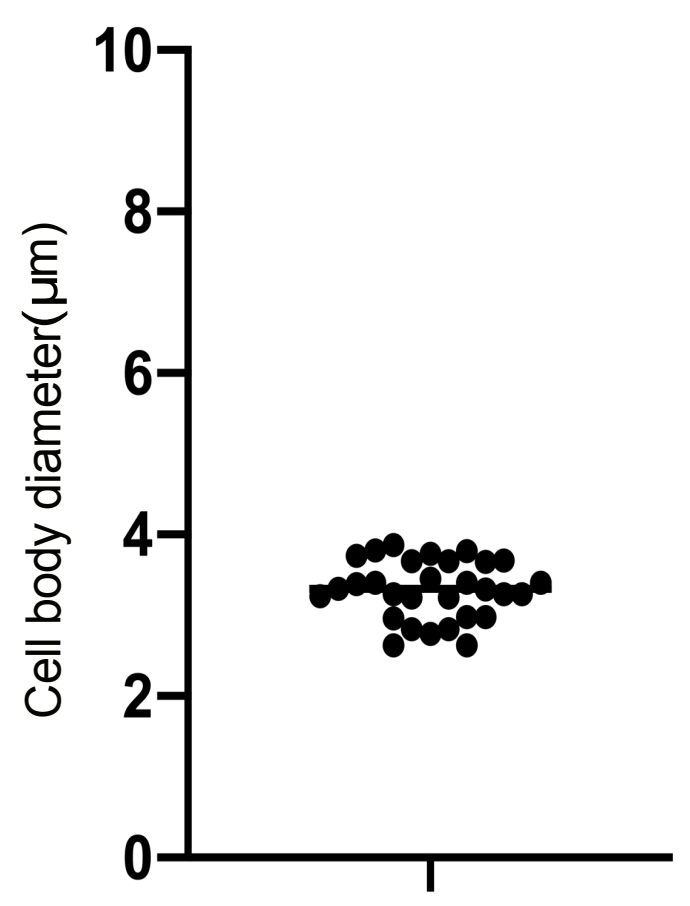

Titanides

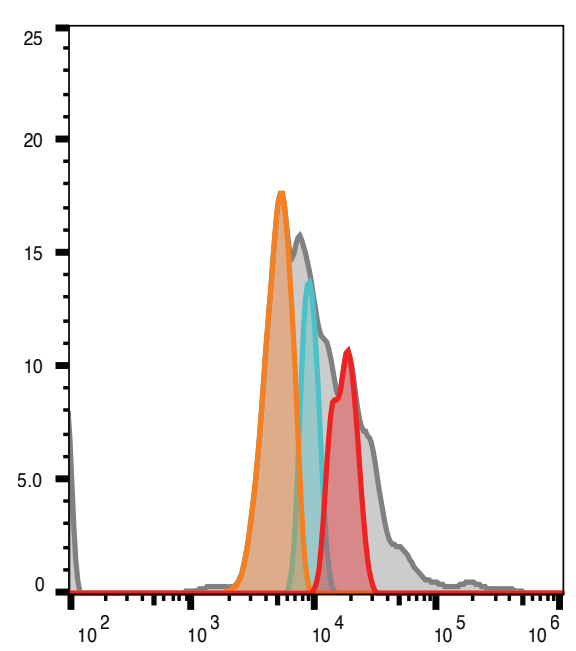

H99 DNA content Mating-induced

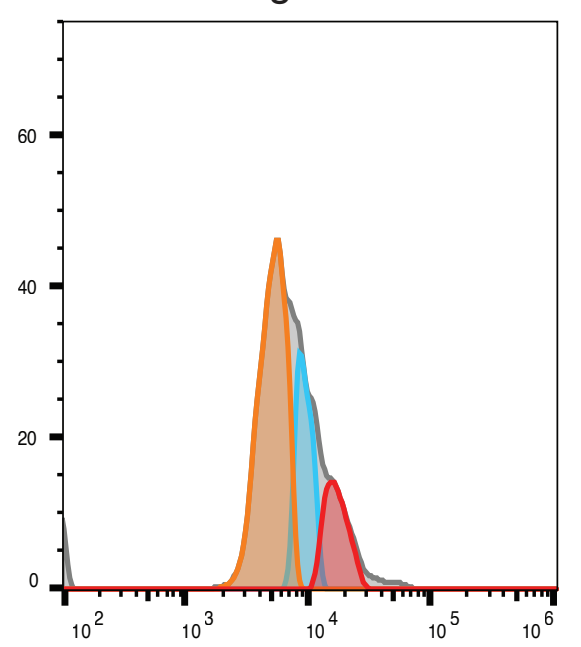

Zc12 DNA content 


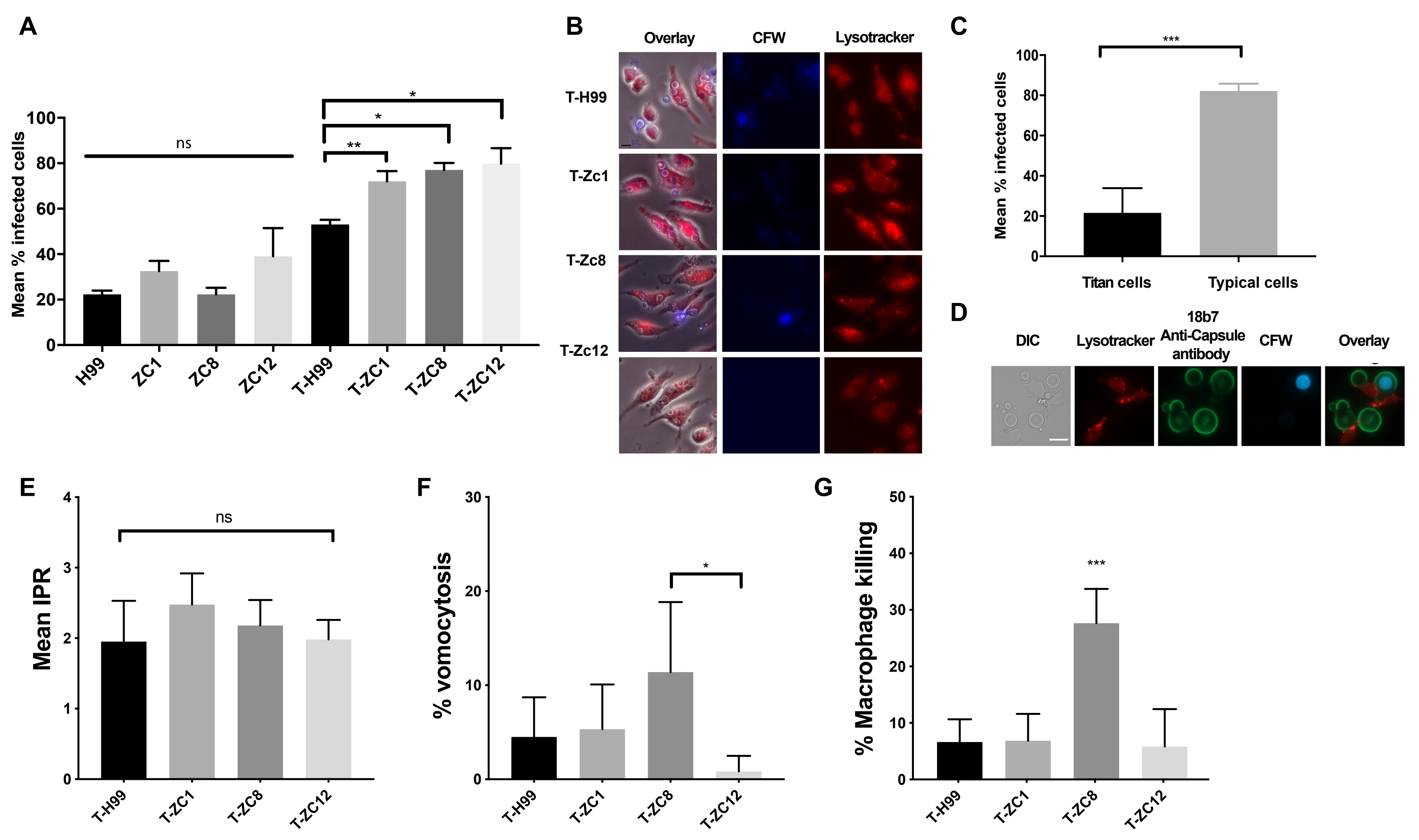



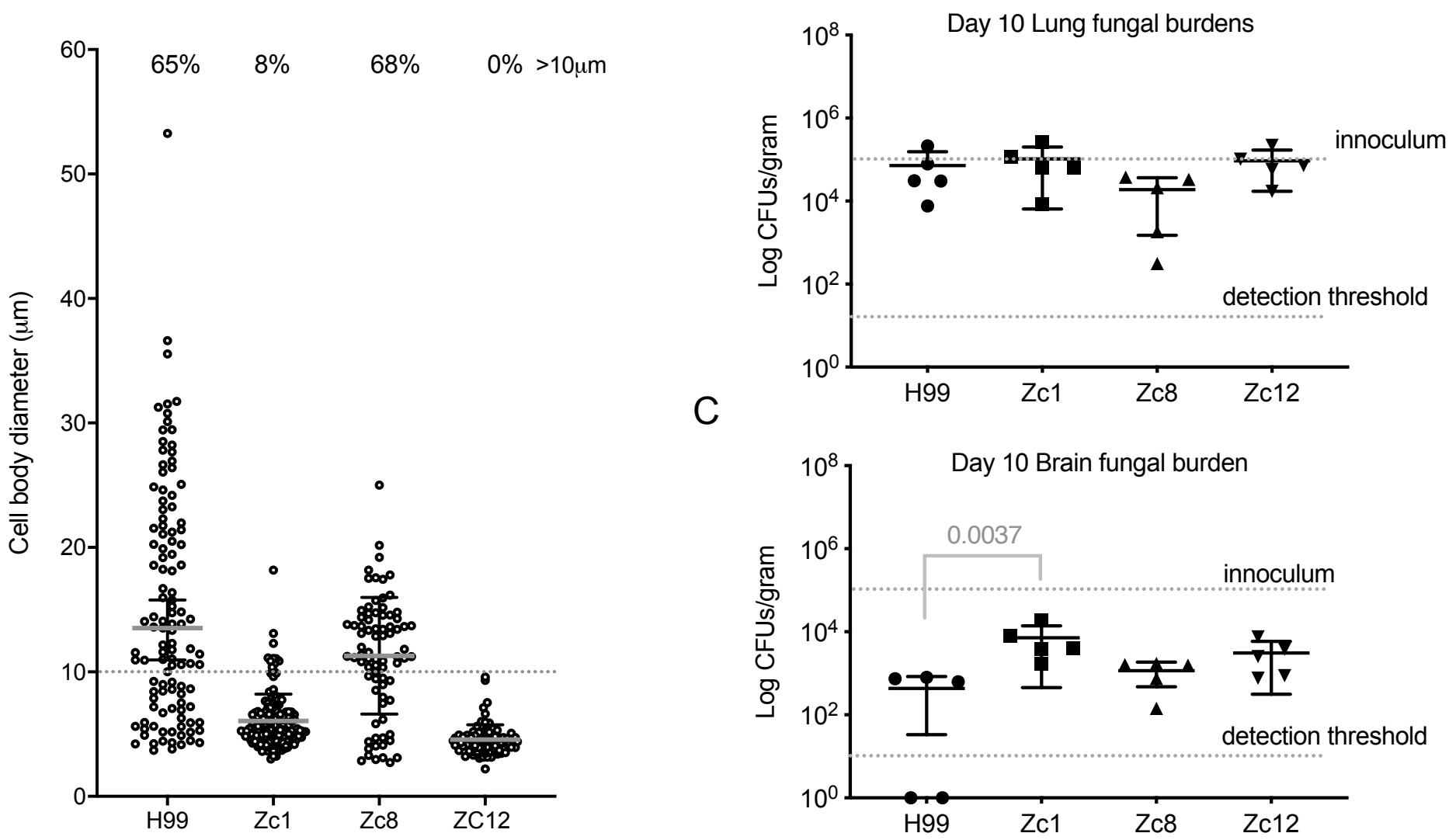

D

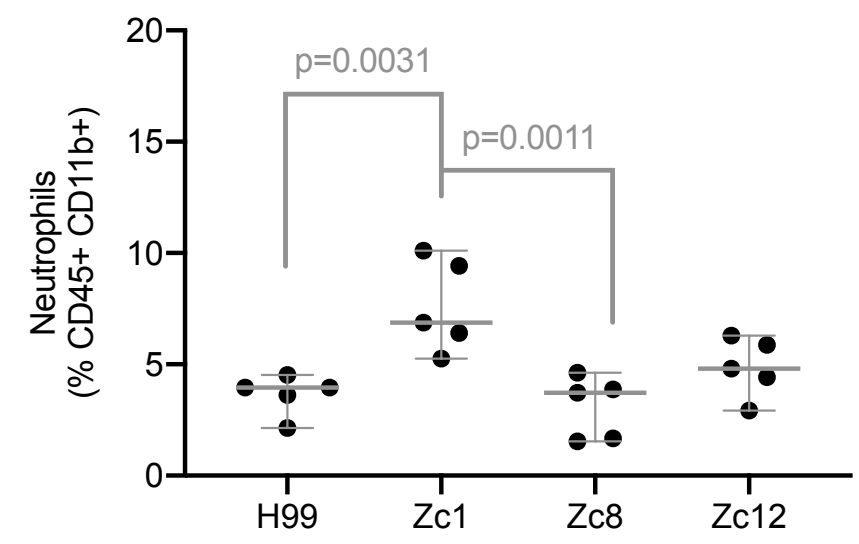

$E$

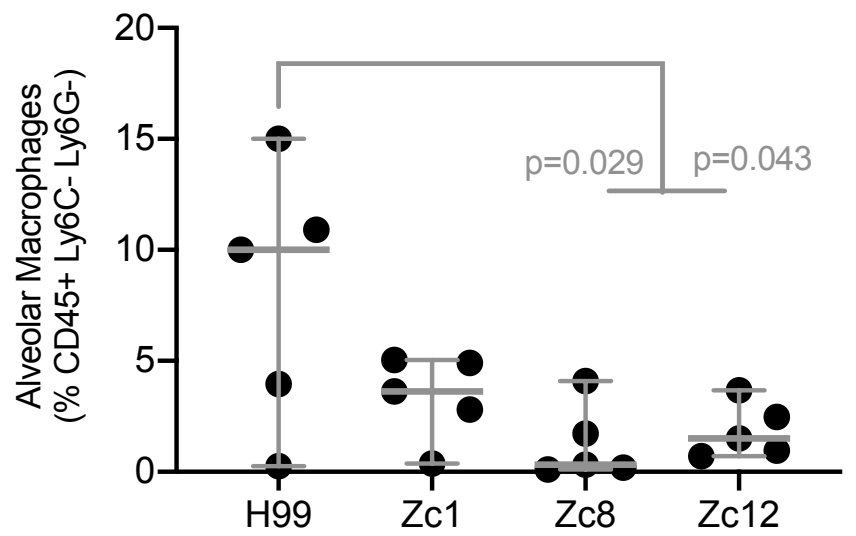


A

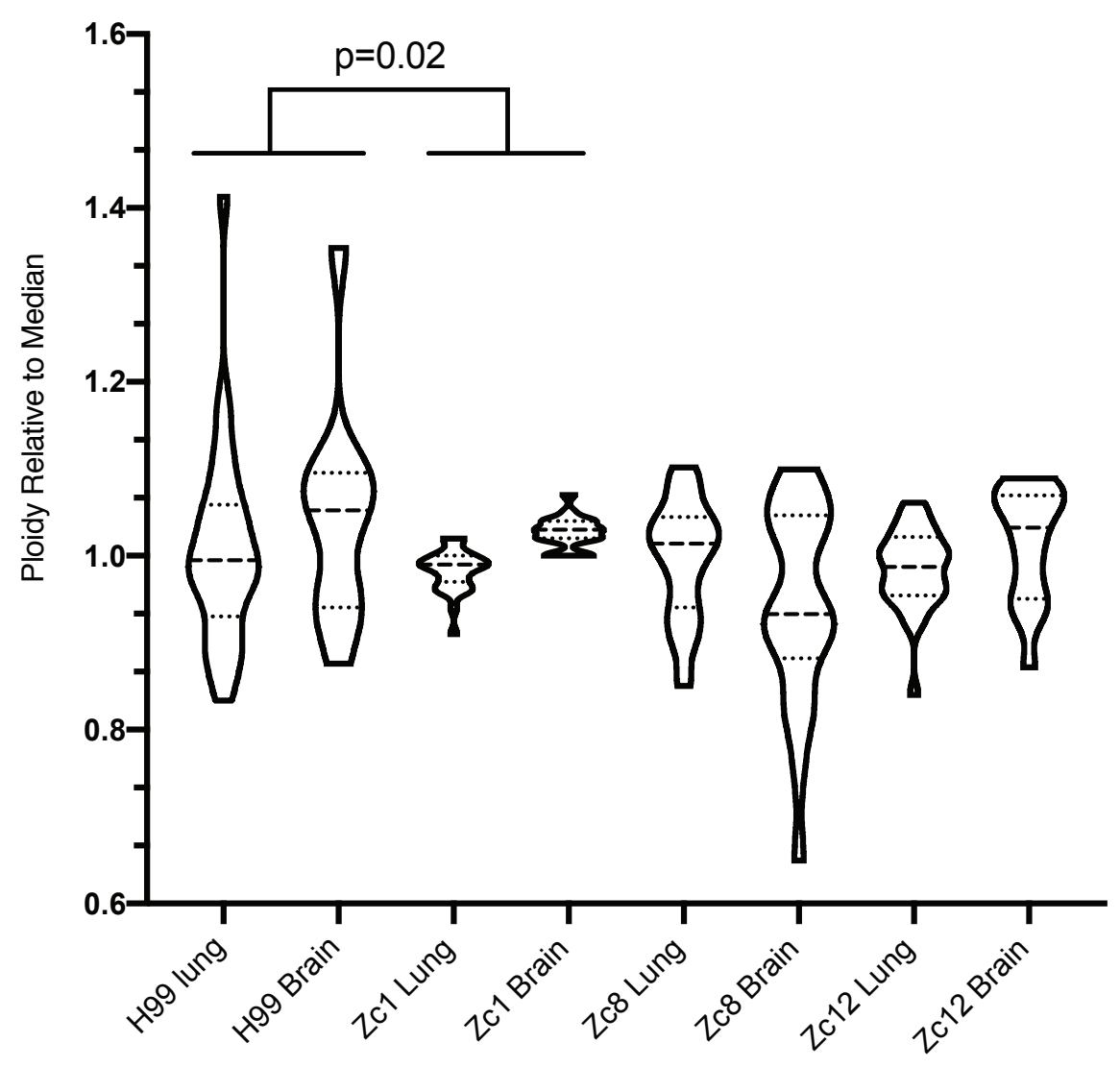

B
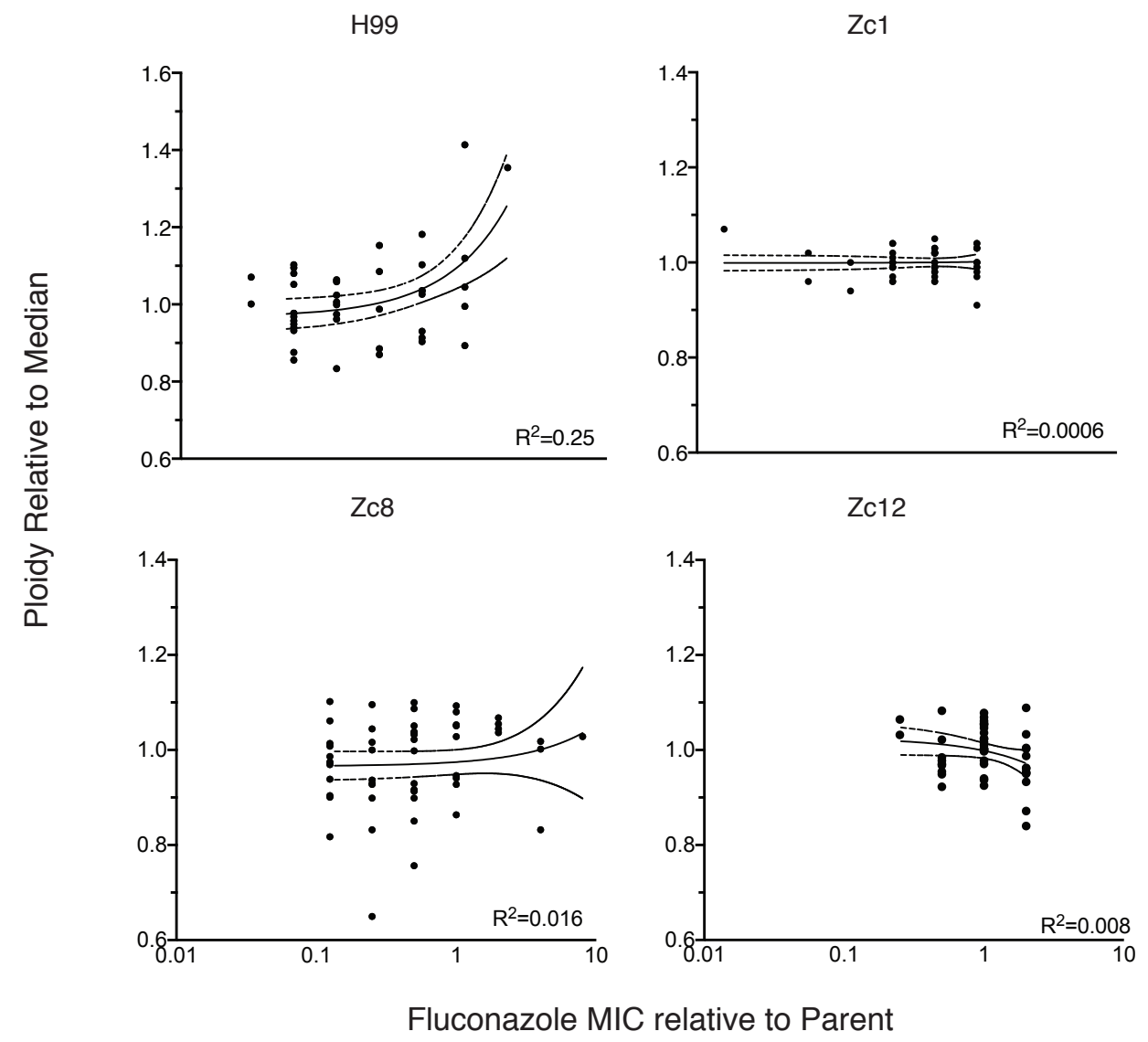